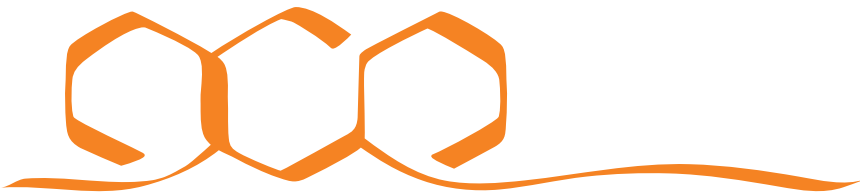 \\ COMMUNICATIONS \\ CHEMISTRY
}

ARTICLE

https://doi.org/10.1038/s42004-021-00449-7 OPEN

\section{Efficient electrocatalytic nitrogen reduction to ammonia with aqueous silver nanodots}

\author{
Wenyi $\mathrm{Li}^{1,2,4}$, Ke $\mathrm{Li}^{1,4}$, Yixing Ye $\mathrm{e}^{1,4}$, Shengbo Zhang ${ }^{1}$, Yanyan Liu ${ }^{1,2}$, Guozhong Wang $\mathbb{1}^{1}$, Changhao Liang ${ }^{1 凶}$, \\ Haimin Zhang (i) ${ }^{1 \times} \&$ Huijun Zhao (D) ${ }^{3}$
}

The electrocatalytic nitrogen $\left(\mathrm{N}_{2}\right)$ reduction reaction (NRR) relies on the development of highly efficient electrocatalysts and electrocatalysis systems. Herein, we report a non-loading electrocatalysis system, where the electrocatalysts are dispersed in aqueous solution rather than loading them on electrode substrates. The system consists of aqueous $\mathrm{Ag}$ nanodots (AgNDs) as the catalyst and metallic titanium ( $\mathrm{Ti}$ ) mesh as the current collector for electrocatalytic NRR. The as-synthesized AgNDs, homogeneously dispersed in $0.1 \mathrm{M} \mathrm{Na}_{2} \mathrm{SO}_{4}$ solution ( $\mathrm{pH}=10.5)$, can achieve an $\mathrm{NH}_{3}$ yield rate of $600.4 \pm 23.0 \mu \mathrm{gh}^{-1} \mathrm{mg}_{\mathrm{Ag}}{ }^{-1}$ with a faradaic efficiency (FE) of $10.1 \pm 0.7 \%$ at $-0.25 \mathrm{~V}$ (vs. RHE). The FE can be further improved to be $20.1 \pm 0.9 \%$ at the same potential by using Ti mesh modified with oxygen vacancy-rich $\mathrm{TiO}_{2}$ nanosheets as the current collector. Utilizing the aqueous AgNDs catalyst, a Ti plate based two-electrode configured flow-type electrochemical reactor was developed to achieve an $\mathrm{NH}_{3}$ yield rate of $804.5 \pm 30.6 \mu \mathrm{g} \mathrm{h}^{-1} \mathrm{mg}_{\mathrm{Ag}}{ }^{-1}$ with a $\mathrm{FE}$ of $8.2 \pm 0.5 \%$ at a voltage of -1.8 $\mathrm{V}$. The designed non-loading electrocatalysis system takes full advantage of the AgNDs' active sites for $\mathrm{N}_{2}$ adsorption and activation, following an alternative hydrogenation mechanism revealed by theoretical calculations.

\footnotetext{
${ }^{1}$ Key Laboratory of Materials Physics, Centre for Environmental and Energy Nanomaterials, Anhui Key Laboratory of Nanomaterials and Nanotechnology, CAS Center for Excellence in Nanoscience, Institute of Solid State Physics, HFIPS, Chinese Academy of Sciences, Hefei 230031, China. ${ }^{2}$ University of Science and Technology of China, Hefei 230026, China. ${ }^{3}$ Centre for Clean Environment and Energy, Griffith University, Gold Coast Campus, Griffith, QLD, Australia.

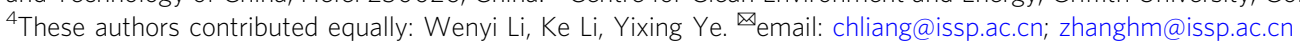


T he fixation of nitrogen $\left(\mathrm{N}_{2}\right)$ to ammonia $\left(\mathrm{NH}_{3}\right)$ at room temperature and atmospheric pressure is an attractive but greatly challenging topic ${ }^{1-3}$. Currently, the over centuryold Haber-Bosch process is still predominant for industrial-scale $\mathrm{NH}_{3}$ production. However, this process needs to consume tremendous energy and natural gas, and concurrently release large amount of $\mathrm{CO}_{2}{ }^{4-6}$, very adverse for energy and environmental sustainability. In recent years, ambient electrocatalytic reduction of $\mathrm{N}_{2}$ to $\mathrm{NH}_{3}$ has attracted increasing attention because of its mild operation conditions, water as the hydrogen source and no $\mathrm{CO}_{2}$ emission ${ }^{5-9}$. However, the electrocatalytic $\mathrm{N}_{2}$ reduction technique is still far away from the practical application because the developed nitrogen reduction reaction (NRR) electrocatalysts possess low $\mathrm{NH}_{3}$ yield and current efficiency, mainly due to extremely high stability of $\mathrm{N}_{2}$ and competitive hydrogen evolution reaction $(\mathrm{HER})^{6-11}$. Therefore, development of highefficiency NRR electrocatalysts and catalysis system is highly desirable for future industrial $\mathrm{NH}_{3}$ production at ambient conditions.

It is well known that reducing the size of electrocatalysts to very small particles has been regarded as an efficient approach to achieve more catalytic active sites for high-efficiency electrocatalysis ${ }^{12-16}$. Owing to unique physical and chemical properties, carbon- and metal-based nanodots (the sizes $<10 \mathrm{~nm}$ ) have been widely applied to photovoltaic devices, environmental fluorescence detection, photocatalysis and electrocatalysis ${ }^{17-19}$. Recently, transition metal oxides and carbides nanodots supported on carbon substrates have been fabricated for the NRR, exhibiting good electrocatalytic activities ${ }^{20-25}$. Although an individual nanodot can provide abundant catalytic active sites (e.g., facet, edge, corner, surface-rich $\mathrm{O} / \mathrm{N}$ functional sites) during electrocatalytic NRR, the nanodots' NRR performance is still very low $\left(\mathrm{NH}_{3}\right.$ yield rate $<\sim 25 \mu \mathrm{g} \mathrm{h}^{-1} \mathrm{mg}^{-1}$ and faradaic efficiency $<$ $\sim 10 \%)$ in the reported literatures ${ }^{20-25}$. This could be primarily attributed to two factors: (i) a limited loading amount of nanodots catalysts on carbon substrates means limited catalytic active sites utilization for NRR; (ii) the loading approach of nanodots catalysts onto the electrode supports readily results in their aggregation during NRR, thus greatly decreasing the exposed catalytic active sites. On the basis of the reported works, some fabricated nanodots can be highly dispersed into aqueous solution. This provides us an opportunity to develop a non-loading electrocatalysis system, capable of employing the nanodots catalysts in their highly dispersed form in aqueous solution, which may be an effective means to sufficiently utilize the exposed catalytic active sites provided by nanodots for high-efficiency NRR. Recently, Ag nanosheets, nanoporous film, triangular nanoplates, $\mathrm{Ag}-\mathrm{Au}, \mathrm{Ag}-\mathrm{Cu}$ alloying materials and $\mathrm{Ag}$ single-atom catalysts, have been developed for electrocatalytic NRR, displaying high NRR activities ${ }^{26-31}$. It can be envisaged that small-sized Ag nanodots with abundant catalytic active sites (e.g., facet, edge, corner etc.) $)^{12,14,16}$ may be more promising candidate for electrocatalytic NRR. However, how to effectively utilize highly dispersed Ag nanodots catalyst in aqueous solution is an important issue that needs to be solved.

Herein, we report the laser-ablation technique to fabricate highly dispersed Ag nanodots (AgNDs) in aqueous solution under $\mathrm{Ar}$ atmosphere ${ }^{32}$. The as-synthesized AgNDs with an average nanodot size of $\sim 2.3 \mathrm{~nm}$ are subsequently employed to a nonloading electrocatalysis system, composed of metallic titanium (Ti) mesh as the current collector and AgNDs as the electrocatalyst dispersed in $0.1 \mathrm{M} \mathrm{Na}_{2} \mathrm{SO}_{4}$ solution $(\mathrm{pH}=10.5)$ for nitrogen reduction reaction (NRR) to $\mathrm{NH}_{3}$. The aqueous AgNDs with abundant catalytic active sites can effectively chemisorb the dissolved $\mathrm{N}_{2}$ molecules in electrolyte, then transfer to the Ti mesh current collector under stirring to accept the $\mathrm{H}^{+} / \mathrm{e}^{-}$attack for
$\mathrm{NH}_{3}$ formation and concurrently regenerate the AgNDs (Supplementary Fig. 1a). Comparatively, in a conventional catalystloading electrocatalysis process (Supplementary Fig. 1b), the assynthesized AgNDs are coated on the electrode substrate (e.g., commercial carbon cloth) with limited loading amount as the cathode, which could arouse an aggregation of AgNDs during NRR and concurrently suffer from the binder's adverse influence (for the electrode preparation) ${ }^{33,34}$. These factors may significantly decrease the NRR performance of AgNDs catalyst. As a result, utilizing the developed non-loading electrocatalysis system, a large $\mathrm{NH}_{3}$ yield rate of $600.4 \pm 23.0 \mu \mathrm{g} \mathrm{h}^{-1} \mathrm{mg}_{\mathrm{Ag}}{ }^{-1}$ with a faradaic efficiency (FE) of $10.1 \pm 0.7 \%$ can be achieved at $-0.25 \mathrm{~V}$ (vs. RHE) in $0.1 \mathrm{M} \mathrm{Na}_{2} \mathrm{SO}_{4}$ electrolyte. The $\mathrm{NH}_{3}$ yield and $\mathrm{FE}$ of this system can be further improved by oxygen vacancies-rich $\mathrm{TiO}_{2}$ nanosheets modified Ti mesh as the current collector, surpassing most of recently reported nanodots and other electrocatalysts for aqueous NRR (Supplementary Table 1). A two-electrode configured flow-type electrochemical reactor using aqueous AgNDs catalyst is therefore developed to obtain an $\mathrm{NH}_{3}$ yield rate of $804.5 \pm 30.6 \mu \mathrm{g} \mathrm{h}^{-1} \mathrm{mg}_{\mathrm{Ag}}{ }^{-1}$ with a FE of $8.2 \pm 0.5 \%$ at a voltage of $-1.8 \mathrm{~V}$. The NRR active mechanism of AgNDs is revealed by our theoretical calculations results.

\section{Results}

Synthesis and characterization of AgNDs. In this work, we employed the laser-ablation technique to fabricate the uniformly dispersed Ag nanodots in deionized water under $\mathrm{Ar}$ atmosphere (Fig. 1a). Figure 1b and Supplementary Fig. 2 show the TEM images of the as-synthesized AgNDs, exhibiting very homogeneous nanodot morphology with an average nanodot size of $\sim 2.3 \mathrm{~nm}$ (inset in Supplementary Fig. 2). The high-resolution TEM (HRTEM) image of the AgNDs (Fig. 1b) shows the lattice spacing of $0.235 \mathrm{~nm}$, corresponding to the (111) plane of fccphase metallic Ag. The corresponding fast Fourier transform (FFT) patterns further confirm this (inset in Fig. 1b). The above results demonstrate that the laser-ablation fabricated AgNDs exhibit highly exposed (111) planes, possibly beneficial for electrocatalysis ${ }^{16,27}$. Supplementary Fig. 3a presents the surface survey XPS spectrum of AgNDs, indicating the presence of $\mathrm{Ag}$ and $\mathrm{O}$ elements. The high-resolution O1s XPS spectrum (Supplementary Fig. 3b) shows that the only peak located at $\sim 532.4 \mathrm{eV}$ is resulted from the surface adsorbed $\mathrm{OH}^{-} / \mathrm{H}_{2} \mathrm{O}^{35}$. In this work, the Zeta potential of AgNDs in aqueous solution was measured to be $-41.7 \mathrm{mV}$, ascribed to the presence of $\mathrm{OH}^{-}$ groups on the surface ${ }^{36}$. This is the reason why the fabricated AgNDs can highly disperse in aqueous solution. The $\mathrm{pH}$ value of AgNDs aqueous solution was measured to be 9.5, supportive of the Zeta potential result. Figure 1c displays the high-resolution Ag 3d XPS spectrum of AgNDs. The peaks concentrated at $\sim 368.1$ and $\sim 374.1 \mathrm{eV}$ can be associated with $\mathrm{Ag} 3 \mathrm{~d} 5 / 2$ and $\mathrm{Ag}$ $3 \mathrm{~d} 3 / 2$, suggesting the existence of metallic $\mathrm{Ag}$ phase in $\mathrm{AgNDs}^{37,38}$. This can be further confirmed by the Raman spectra characterization. As shown in Fig. 1d, the peaks concentrated at $490,608,801$ and $1058 \mathrm{~cm}^{-1}$ for all samples can be indexed to four-membered $\mathrm{SiO}$ rings, three-membered $\mathrm{SiO}$ rings, $\mathrm{Si}-\mathrm{O}-\mathrm{Si}$ and $\mathrm{Si}-\mathrm{OH}$ originated from quartz glass substrate, respectively ${ }^{39}$. Comparatively, the AgNDs sample exhibits the similar Raman peaks as quartz glass substrate, meaning that no oxidation-state $\mathrm{Ag}$ is existent (e.g., $\mathrm{Ag}_{2} \mathrm{O}$ nanoparticles $\left(\mathrm{Ag}_{2} \mathrm{ONPs}\right)$, typical $\mathrm{Ag}-\mathrm{O}$ peaks at $470,675,685,830 \mathrm{~cm}^{-1}$ and O-O peak at $930 \mathrm{~cm}^{-1}$ can be confirmed in our $\mathrm{Ag}_{2} \mathrm{ONPs}$ refs. ${ }^{35,40,41}$ ). The above results demonstrate that highly dispersed $\mathrm{Ag}$ nanodots in aqueous solution are successfully achieved by the laser-ablation technique, possibly providing abundant active sites for high-efficiency electrocatalysis ${ }^{42}$. 

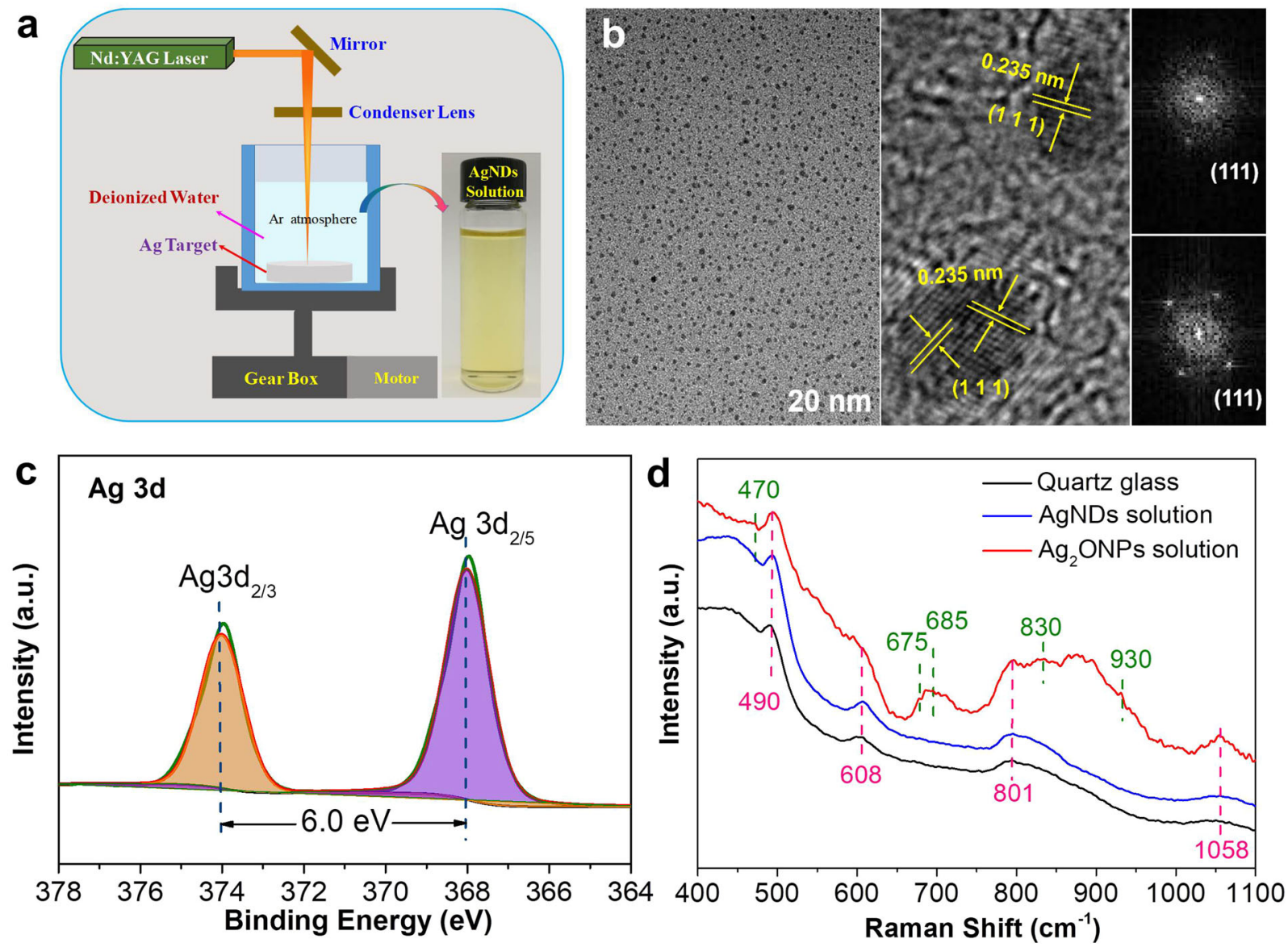

Fig. 1 Characteristics of AgNDs. a Schematic illustration of the fabrication process of Ag nanodots (AgNDs) solution (inset of optical photograph of AgNDs solution) by the laser-ablation technique. b TEM and HRTEM images (inset of corresponding FFT patterns) of AgNDs. c High-resolution Ag 3d XPS spectrum of AgNDs. d Raman spectra of quartz glass substrate, $\mathrm{AgNDs}$ and $\mathrm{Ag}_{2} \mathrm{ONPs}_{\mathrm{N}}$ reference.

NRR performance evaluation. Recently, transition metal oxides and carbides nanodots such as $\mathrm{CoO}, \mathrm{CuO}, \mathrm{NiO}, \mathrm{ZnO}$ and $\mathrm{MoC}$ have been investigated as the electrocatalysts for NRR, exhibiting good catalytic activities ${ }^{20-23,25}$. However, these obtained nanodots are exclusively anchored on carbon substrates in the fabrication process, meaning that the nanodots loading amount could be very limited, thus resulting in low electrocatalytic NRR performance ${ }^{20-25,43,44}$. In this work, we utilized the developed nonloading electrocatalysis system to evaluate the NRR activity of AgNDs uniformly dispersed in $0.1 \mathrm{M} \mathrm{Na}_{2} \mathrm{SO}_{4}$ solution $(\mathrm{pH}=$ 10.5) (see Experimental Section). Prior to the NRR experiments, the as-synthesized AgNDs were first mixed with Ar-saturated $0.1 \mathrm{M} \mathrm{Na} \mathrm{Na}_{2} \mathrm{SO}_{4}$ solution $(\mathrm{pH}=10.5)$, then transferred to the electrochemical cell to perform the NRR measurements. It should be noted that the used $\mathrm{Ar}$ and $\mathrm{N}_{2}\left(\right.$ or $\left.{ }^{15} \mathrm{~N}_{2}\right)$ feeding gases need to be first pre-purified by a similar protocol as previous works reported to remove the possible interferences of $\mathrm{NH}_{3}$ and $\mathrm{NO}_{\mathrm{x}}$ in Ar or $\mathrm{N}_{2}\left(\text { or }{ }^{15} \mathrm{~N}_{2}\right)^{45,46}$. Supplementary Fig. 4 shows the experimental setup. A Cu-Fe-Al catalyst (Supplementary Fig. 5) unit was used to remove $\mathrm{NO}_{\mathrm{x}} \cdot \mathrm{A} \mathrm{CrO}_{3}$ column was used to eliminate any possible $\mathrm{NO}$ interference by converting $\mathrm{NO}$ to water-soluble $\mathrm{NO}_{2}$, which can then be removed by $\mathrm{H}_{2} \mathrm{SO}_{4}$ solution and distilled water absorption units. And the produced tail gas was absorbed by two-series tail gas absorbers (each absorber contains $20 \mathrm{~mL}$ of $1.0 \mathrm{mM} \mathrm{H}_{2} \mathrm{SO}_{4}$ solution) to prevent the produced $\mathrm{NH}_{3}$ with $\mathrm{N}_{2}$ flow into air during $\mathrm{NRR}^{46}$. Therefore, the solution samples obtained from cathodic compartment, anodic compartment and tail gas absorbers will be all determined to analyze the yielded NRR products. Figure 2a shows the linear sweep voltammetry (LSV) curves of $\mathrm{Ti}$ mesh with and without AgNDs in Ar- and $\mathrm{N}_{2}$ - saturated $0.1 \mathrm{M} \mathrm{Na}_{2} \mathrm{SO}_{4}$ solutions $(\mathrm{pH}=$ 10.5 ) with a scan rate of $5.0 \mathrm{mV} \mathrm{s}^{-1}$. The results indicate that in the investigated potential range, ignorable change in the cathodic current is observable for Ti mesh without AgNDs in both Ar- and $\mathrm{N}_{2}$-saturated $0.1 \mathrm{M} \mathrm{Na} \mathrm{SO}_{4}$ solutions, suggesting poor $\mathrm{NRR}$ activity of Ti mesh. When the AgNDs were introduced to $0.1 \mathrm{M}$ $\mathrm{Na}_{2} \mathrm{SO}_{4}$ solution with a concentration of $0.0015 \mathrm{mg} \mathrm{mL}^{-1}$, the cathodic currents are obviously increased in Ar-saturated $0.1 \mathrm{M}$ $\mathrm{Na}_{2} \mathrm{SO}_{4}$ solution. Considering no oxidation-state Ag existence in AgNDs, the enhanced cathodic currents with applied negative potential in Ar-saturated solution are mainly attributed to the occurred hydrogen evolution reaction (HER) ${ }^{47-49}$. Comparatively, the cathodic currents in LSV curve are apparently increased with applied negative potential in $\mathrm{N}_{2}$-saturated solution with AgNDs incorporation, suggesting that the AgNDs are electrocatalytic activity toward the NRR. In this study, the yielded NRR products including possible $\mathrm{NH}_{3}$ and/or $\mathrm{N}_{2} \mathrm{H}_{4}$ were quantitatively analyzed by the indophenol blue method (Supplementary Fig. 6) and the Watt and Chrisp method (Supplementary Fig. 7) ${ }^{50,51}$. The preliminary experimental results confirm that only $\mathrm{NH}_{3}$ product can be detected and $\mathrm{N}_{2} \mathrm{H}_{4}$ is ignorable (Supplementary Fig. 7d). Furthermore, $\mathrm{NH}_{3}$ product can be detected in both cathodic and anodic compartments, undetectable in the tail gas absorbers. In subsequent experiments, the obtained $\mathrm{NH}_{3}$ yield were therefore calculated from the total yielded $\mathrm{NH}_{3}$ amount detected in the samples obtained from both cathodic and anodic compartments 

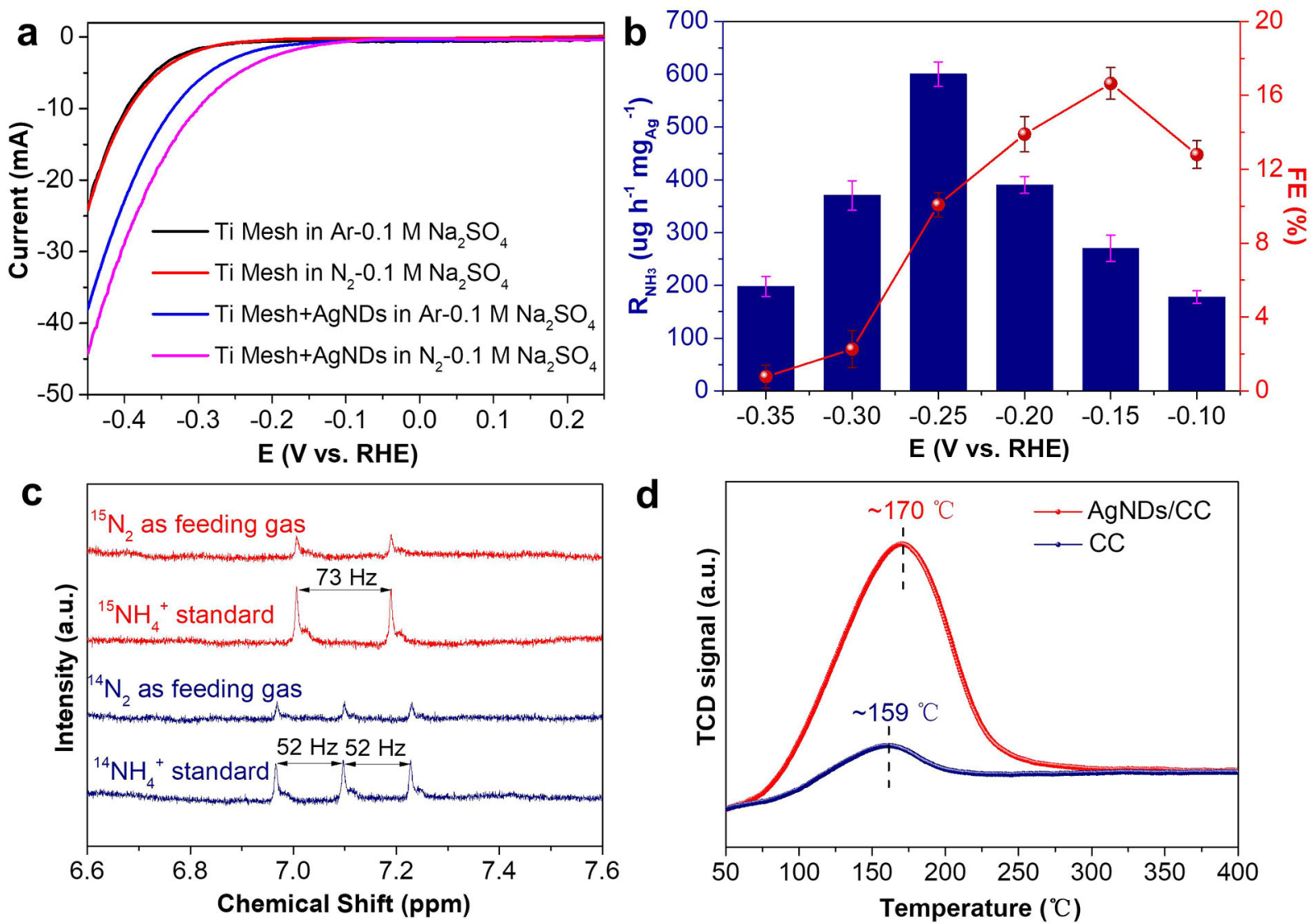

Fig. 2 NRR evaluation of AgNDs in the non-loading electrocatalysis system. a LSV curves of Ti mesh with and without AgNDs incorporation in Ar- and $\mathrm{N}_{2}$-saturated $0.1 \mathrm{M} \mathrm{Na}_{2} \mathrm{SO}_{4}$ solutions $(\mathrm{pH}=10.5)$. b The dependence of $\mathrm{NH}_{3}$ yield rate and faradaic efficiency of AgNDs catalyst on the applied potential. The error bars correspond to the standard deviations of three independent measurements. ${ }^{1} \mathrm{H}$ NMR spectra of the samples obtained using ${ }^{15} \mathrm{~N}_{2}$ and ${ }^{14} \mathrm{~N}_{2}$ as the feeding gases and standard ${ }^{15} \mathrm{NH}_{4}{ }^{+}$and ${ }^{14} \mathrm{NH}_{4}{ }^{+}$samples. $\mathbf{d ~ N} \mathrm{N}_{2}$-TPD curves of $\mathrm{CC}$ and AgNDs/CC.

(Supplementary Fig. 8a-c). The detected $\mathrm{NH}_{3}$ in anodic compartment is mainly attributed to the diffusion of the produced $\mathrm{NH}_{3}$ in cathodic compartment through the proton exchange membrane (Nafion 117 in our case) ${ }^{52}$. Figure $2 \mathrm{~b}$ shows the dependence of $\mathrm{NH}_{3}$ yield rate (denoted as $\mathrm{R}_{\mathrm{NH}}$ ) and faradaic efficiency (FE) on the applied potential in $\mathrm{N}_{2}$-saturated $0.1 \mathrm{M}$ $\mathrm{Na}_{2} \mathrm{SO}_{4}$ solution $(\mathrm{pH}=10.5)$ with AgNDs incorporation for $1 \mathrm{~h}$ NRR. The corresponding chronoamperometric profiles obtained at different potentials are shown in Supplementary Fig. 8d. As shown in Fig. $2 b$, the $\mathrm{R}_{\mathrm{NH} 3}$ is increased with the applied cathodic potential and the largest $\mathrm{R}_{\mathrm{NH} 3}$ can be achieved to be $600.4 \pm$ $23.0 \mu \mathrm{g} \mathrm{h}^{-1} \mathrm{mg}_{\mathrm{Ag}}{ }^{-1}$ with a FE of $10.1 \pm 0.7 \%$ at $-0.25 \mathrm{~V}$ (vs. RHE). The highest FE of $16.7 \pm 0.9 \%$ can be obtained at -0.15 $\mathrm{V}$ (vs. RHE). When the applied potential is over $-0.25 \mathrm{~V}$ (vs. $\mathrm{RHE}$ ), the $\mathrm{R}_{\mathrm{NH} 3}$ and FE are obviously decreased, mainly owing to the competitive HER process concurrently occurred on the $\mathrm{AgNDs}^{25,53}$. In addition, we also performed the experiment to quantify the produced $\mathrm{H}_{2}$ during NRR. At $-0.25 \mathrm{~V}$ (vs. RHE) in $\mathrm{N}_{2}$-saturated $0.1 \mathrm{M} \mathrm{Na}_{2} \mathrm{SO}_{4}$ electrolyte $(\mathrm{pH}=10.5)$ for $1 \mathrm{~h} \mathrm{NRR}$ (Supplementary Fig. 9a), the amount of $\mathrm{H}_{2}$ produced was $778.2 \mu \mathrm{L}$ (Supplementary Fig. 9d) calculated according to $\mathrm{H}_{2}$ standard curve (Supplementary Fig. 9b, c), while the amount of yielded $\mathrm{NH}_{3}$ was $0.93 \mu \mathrm{g} \mathrm{mL}^{-1}$. Based on the time-dependent current curve (Supplementary Fig. 9a), the faradaic efficiency (FE) of $\mathrm{H}_{2}$ produced was calculated to be $\sim 88.3 \%$, while the FE of $\mathrm{NH}_{3}$ yielded was $\sim 10.2 \%$. The total FE is $\sim 98.5 \%$. Considering the analytical errors involved, the nearly $100 \%$ total FE obtained from the measured $\mathrm{H}_{2}$ and $\mathrm{NH}_{3}$ further confirms the reported $\mathrm{FE}$ for $\mathrm{NH}_{3}$ production.
To evaluate the stability of AgNDs toward the NRR, we performed the NRR experiment at $-0.25 \mathrm{~V}$ (vs. RHE) for $5 \mathrm{~h}$. A slight decay of the cathodic current can be found in the timecurrent profile (Supplementary Fig. 10a), and $\mathrm{R}_{\mathrm{NH} 3}$ is found to be slightly decreased with increasing the time and the $\mathrm{R}_{\mathrm{NH} 3}$ after $5 \mathrm{~h}$ of NRR is measured to be $578.4 \pm 22.1 \mu \mathrm{g} \mathrm{h}^{-1} \mathrm{mg}_{\mathrm{Ag}}{ }^{-1}$, indicating good NRR stability of the AgNDs in the non-loading electrocatalysis system. The corresponding $\mathrm{R}_{\mathrm{NH} 3}$ and $\mathrm{NH}_{3}$ yield measured every $1 \mathrm{~h}$ during $5 \mathrm{~h}$ NRR are shown in Supplementary Fig. 10b, c. The in situ time-dependence Raman measurements were also conducted to confirm the structural change of AgNDs during durability test. As shown in Supplementary Fig. 11, all Raman spectra of the AgNDs in $\mathrm{N}_{2}$-saturated $0.1 \mathrm{M} \mathrm{Na} \mathrm{NO}_{4}$ solution $(\mathrm{pH}=10.5)$ with reaction time are almost identical to that of quartz glass substrate and no Raman peaks of oxidationstate $\mathrm{Ag}$ appear, such as $\mathrm{Ag}_{2} \mathrm{O}$, meaning that the metallic $\mathrm{Ag}$ phase is still dominant in the AgNDs during durability test. This can be further confirmed by the TEM characterization results of AgNDs after $5 \mathrm{~h} \mathrm{NRR} \mathrm{measurement} \mathrm{(Supplementary} \mathrm{Fig.} \mathrm{12),} \mathrm{and}$ the AgNDs are still uniformly dispersed in the solution and remain well metallic Ag nature. This also means that the abundant catalytic active sites exposed on AgNDs are still maintained well, resulting in high NRR activity during durability test. In addition, the XPS analysis results show that compared to the pristine AgNDs, besides of $\mathrm{Ag}$ and $\mathrm{O}$ elements, additional $\mathrm{N}$ element can be also detected for the AgNDs sample after $5 \mathrm{~h}$ NRR (Supplementary Fig. 13a). The high-resolution N 1 s XPS spectrum (Supplementary Fig. 13b) of AgNDs after $5 \mathrm{~h}$ NRR displays a peak at binding energy of $\sim 400.2 \mathrm{eV}$, possibly owing to 
the formed $\mathrm{N}$-intermediates (e.g., $-\mathrm{NH}_{\mathrm{x}}$ ) during $\mathrm{NRR}^{54-56}$. In addition, the high-resolution $\mathrm{Ag} 3 \mathrm{~d}$ and $\mathrm{O} 1 \mathrm{~s}$ XPS spectra (Supplementary Fig. 13c, d) of AgNDs after $5 \mathrm{~h}$ NRR have no obvious change compared to the pristine AgNDs, further demonstrating high NRR stability of AgNDs. To assure the reproductivity of a non-loading electrocatalysis system for highefficiency NRR, another two batches of AgNDs aqueous solution were fabricated by the laser-ablation technique. The TEM and HRTEM images indicate that all AgNDs samples exhibit homogeneously dispersed nanodot morphology with the (111) plane of fcc-phase metallic Ag (Supplementary Fig. 14a, b), confirming high reproductivity of the fabricated AgNDs catalyst by the laser-ablation technique. To further confirm the reproductivity of AgNDs catalyst for high-efficiency NRR, we also performed the electrocatalytic NRR experiments using another two batches of AgNDs catalysts at $-0.25 \mathrm{~V}$ (vs. RHE) for $1 \mathrm{~h}$. The results show that the $\mathrm{R}_{\mathrm{NH} 3}$ of the two AgNDs catalysts can be achieved to be $604.9 \pm 17.0 \mu \mathrm{g} \mathrm{h}^{-1} \mathrm{mg}_{\mathrm{Ag}}{ }^{-1}$ and $591.9 \pm 25.0 \mu \mathrm{g} \mathrm{h}^{-1} \mathrm{mg}_{\mathrm{Ag}}{ }^{-1}$ with FE of $10.8 \pm 0.7 \%$ and $9.8 \pm 0.6 \%$ respectively (Supplementary Fig. 14c), close to those of the reported AgNDs catalyst in this work, giving a $\mathrm{R}_{\mathrm{NH} 3}$ of $600.4 \pm$ $23.0 \mu \mathrm{g} \mathrm{h}^{-1} \mathrm{mg}_{\mathrm{Ag}}{ }^{-1}$ and a FE of $10.1 \pm 0.7 \%$. The above results demonstrate high reproducibility of this AgNDs-incorporated non-loading electrocatalysis system for high-efficiency NRR.

To eliminate the environmental interferences on the yielded $\mathrm{NH}_{3}$ during NRR, several control experiments were carried out in this work, including $0.1 \mathrm{M} \mathrm{Na}_{2} \mathrm{SO}_{4}$ solution $(\mathrm{pH}=10.5)$ (blank solution), $0.1 \mathrm{M} \mathrm{Na}_{2} \mathrm{SO}_{4}$ solution ( $\mathrm{pH}=10.5$ ) with $\mathrm{AgNDs}$ under open-circuit condition (open-circuit), and Ar-saturated $0.1 \mathrm{M}$ $\mathrm{Na}_{2} \mathrm{SO}_{4}$ solution $(\mathrm{pH}=10.5)$ with AgNDs at $-0.25 \mathrm{~V}$ (vs. RHE) for $1 \mathrm{~h}$ (Ar-saturated solution). The results demonstrate that ignorable $\mathrm{NH}_{3}$ product is detectable for all cases (Supplementary Fig. 15), thus eliminating any noticeable environmental interference to the yielded $\mathrm{NH}_{3}$ from the AgNDs catalyzed NRR. In addition, we also compared the yielded $\mathrm{NH}_{3}$ amount using $\mathrm{Ti}$ mesh electrode without AgNDs incorporation in $\mathrm{N}_{2}$-saturated $0.1 \mathrm{M} \mathrm{Na}_{2} \mathrm{SO}_{4}$ solution $(\mathrm{pH}=10.5)$ at $-0.25 \mathrm{~V}$ (vs. $\left.\mathrm{RHE}\right)$ for $1 \mathrm{~h}$ NRR. Obviously, inferior NRR activity can be achieved for the Ti mesh without AgNDs (Supplementary Fig. 15). Moreover, To eliminate the interferences of possible $\mathrm{NO}_{\mathrm{x}}$ (including $\mathrm{NO}$ and $\mathrm{NO}_{2}$ ) toward on the yielded $\mathrm{NH}_{3}$ during NRR, ion chromatography (IC 6000, Wayeal Co. Ltd. China) measurement was performed to verify whether there is $\mathrm{NO}_{\mathrm{x}}$ present at all key stages of the experiment. As shown in Supplementary Fig. 16, no detectable $\mathrm{NO}_{2}{ }^{-}$and $\mathrm{NO}_{3}{ }^{-}$can be observed in all sample solution, demonstrating that the yielded $\mathrm{NH}_{3}$ are resulted entirely from the electrocatalytic NRR process.

To further confirm the yielded $\mathrm{NH}_{3}$ from the AgNDs catalyzed NRR, we subsequently conducted the ${ }^{15} \mathrm{~N}$ isotopic labeling experiments ${ }^{45,57}$. The ${ }^{1} \mathrm{H}$ nuclear magnetic resonance (NMR) spectra were obtained using ${ }^{14} \mathrm{~N}_{2}$ and ${ }^{15} \mathrm{~N}_{2}$ as the feeding gases in AgNDs incorporated $0.1 \mathrm{M} \mathrm{Na}_{2} \mathrm{SO}_{4}$ solution $(\mathrm{pH}=10.5)$ at $-0.25 \mathrm{~V}$ (vs. RHE) over $1 \mathrm{~h}$ NRR period. Figure $2 \mathrm{c}$ shows the ${ }^{1} \mathrm{H}$ NMR spectra of the standards and the yielded ${ }^{14} \mathrm{NH}_{4}{ }^{+}$and ${ }^{15} \mathrm{NH}_{4}{ }^{+}$products in the NRR samples, confirming that the yielded $\mathrm{NH}_{3}$ is indeed exclusively resulted from the AgNDs catalyzed NRR. The quantitative analysis results, based on the standard ${ }^{14} \mathrm{NH}_{4}{ }^{+}$and ${ }^{15} \mathrm{NH}_{4}{ }^{+1} \mathrm{H}$ NMR spectra and corresponding calibration curves (Supplementary Fig. 17) ${ }^{25}$ confirm that the concentration of the yielded ${ }^{14} \mathrm{NH}_{4}{ }^{+}$and ${ }^{15} \mathrm{NH}_{4}{ }^{+}$(normalized to the yielded $\mathrm{NH}_{3}$ concentration in cathodic compartment with $50 \mathrm{~mL}$ of electrolyte) is 0.86 and $0.92 \mu \mathrm{g} \mathrm{mL}^{-1}$ respectively, almost identical to the results $\left(0.90\right.$ and $0.88 \mu \mathrm{g} \mathrm{mL} L^{-1}$ for ${ }^{14} \mathrm{NH}_{4}{ }^{+}$ and ${ }^{15} \mathrm{NH}_{4}{ }^{+}$, respectively) obtained from the indophenol blue detection method. To further illustrate the advantages of the used non-loading electrocatalysis system for high-efficiency NRR, we also carried out several comparison experiments. The assynthesized AgNDs were coated on the commercial carbon cloth (CC) substrate to prepare AgNDs/CC electrode, which was used as the cathode for NRR measurement at $-0.25 \mathrm{~V}$ (vs. RHE) in $\mathrm{N}_{2}$-saturated $0.1 \mathrm{M} \mathrm{Na}_{2} \mathrm{SO}_{4}$ solution $(\mathrm{pH}=10.5)$ for $1 \mathrm{~h}$ using a conventional catalyst-loading electrocatalysis system (Supplementary Fig. 1b). For meaningful comparison, $\mathrm{Ag}_{2} \mathrm{O}$ nanoparticles $\left(\mathrm{Ag}_{2} \mathrm{ONPs}\right)$ with an average particle size of $\sim 13 \mathrm{~nm}$ (Supplementary Fig. 18) were fabricated by treating $\mathrm{O}_{2}$-saturated AgNDs solution at $50^{\circ} \mathrm{C}$ for $1 \mathrm{~h}$ and $\mathrm{Ag}$ nanoparticles (AgNPs) with an average particle size of $\sim 17 \mathrm{~nm}$ obtained by the laserablation technique (Supplementary Fig. 19), were also evaluated for the NRR under the identical experimental conditions. The results (Supplementary Fig. 20) show that after $1 \mathrm{~h}$ NRR, the AgNDs/CC, $\mathrm{Ag}_{2} \mathrm{ONPs} / \mathrm{CC}$ and $\mathrm{AgNPs} / \mathrm{CC}$ can give an $\mathrm{NH}_{3}$ yield rate of $80.1 \pm 1.5,58.0 \pm 2.1$ and $66.0 \pm 1.3 \mu \mathrm{g} \mathrm{h}^{-1} \mathrm{mg}_{\text {cat. }}{ }^{-1}$ with a FE of $6.2 \pm 0.1 \%, 4.9 \pm 0.2 \%$ and $5.3 \pm 0.2 \%$ at $-0.25 \mathrm{~V}$ (vs. RHE), respectively. Among all investigated catalysts, the $\mathrm{Ag}_{2} \mathrm{ONPs} / \mathrm{CC}$ exhibits the lowest NRR activity, mainly owing to an easy reductive property of $\mathrm{Ag}_{2} \mathrm{O}$ to consume large number of electrons but not for the $\mathrm{NRR}^{35,37,38}$. Comparatively, the AgNDs/CC gives higher NRR activity than that of AgNPs/CC, indicating that $\mathrm{Ag}$ nanodots with smaller sizes may provide more active sites for the NRR. The $\mathrm{NH}_{3}$ yield rate of AgNDs catalyst using non-loading electrocatalysis system is almost 7.5 times of that obtained from the AgNDs/CC using the conventional catalyst-loading electrocatalysis system. This is primarily ascribed to the $\mathrm{Ag}$ nanodots uniformly dispersed in solution capable of providing more catalytic active sites for NRR, while the limited loading amount of AgNDs on CC and easy aggregation to form large-sized Ag nanoparticles during NRR could result in significantly decreased NRR performance. The highly dispersed Ag nanodots in solution can supply abundant active sites ${ }^{12,14,16}$ for chemically adsorbing $\mathrm{N}_{2}$ molecules, and then these chemisorptive $\mathrm{N}_{2}$ molecules on AgNDs accept the attack of $\mathrm{H}^{+} / \mathrm{e}^{-}$at Ti mesh to form $\mathrm{NH}_{3}$ molecules. This can be further verified by the $\mathrm{N}_{2}$ temperatureprogrammed desorption (TPD) measurement (Fig. 2d). Compared to the CC substrate, AgNDs/CC obviously displays a dramatically enhanced $\mathrm{N}_{2}$ desorption peak at $\sim 170^{\circ} \mathrm{C}$, meaning superior adsorption capability of AgNDs toward $\mathrm{N}_{2}{ }^{31}$. In addition, we also investigated the influence of current collector using commercial carbon cloth (CC) to replace metallic Ti mesh in the non-loading electrocatalysis system. The results (Supplementary Fig. 21) show that the $\mathrm{NH}_{3}$ yield rate of AgNDs catalyst using commercial carbon cloth (CC) as the current collector can give an $\mathrm{NH}_{3}$ yield rate of $402.3 \pm 15.0 \mathrm{\mu g} \mathrm{h}^{-1} \mathrm{mg}_{\mathrm{Ag}}{ }^{-1}$ with a FE of $16.7 \pm 0.7 \%$ at $-0.25 \mathrm{~V}$ (vs. RHE) after $1 \mathrm{~h}$ NRR measurement. The higher $\mathrm{NH}_{3}$ yield rate using metallic Ti mesh as the current collector could be due to its good electrical conductivity with superior dynamic NRR process. Furthermore, the concentration effect of AgNDs on the $\mathrm{NH}_{3}$ yield rate was also investigated in this work. As seen in Supplementary Fig. 22, the $\mathrm{NH}_{3}$ yield is linearly increased with increasing the AgNDs concentration, but the change in the $\mathrm{NH}_{3}$ yield rate normalized to per milligram of AgNDs is not obvious with increasing the AgNDs concentration, possibly owing to lower $\mathrm{N}_{2}$ solubility in aqueous solution and/or mass transport influence with higher AgNDs concentration in the non-loading electrocatalysis system.

Ti plate-based two-electrode configured flow-type electrochemical reactor. Except for high-efficient electrocatalysts, design and development of high-performance electrochemical NRR reactors are also critically important for $\mathrm{NH}_{3}$ production. Several reported works have verified that the flow-type electrochemical 
a
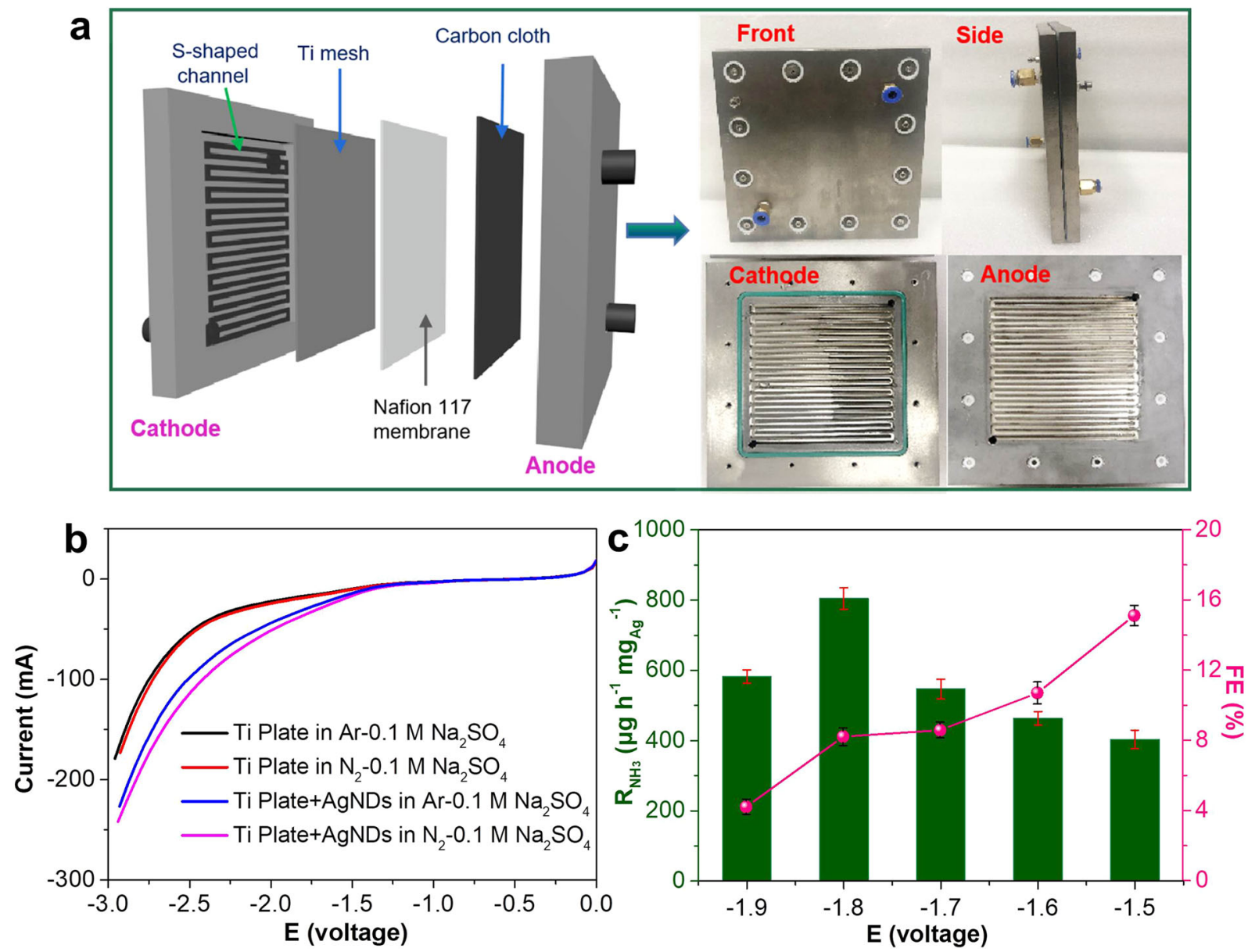

Fig. 3 NRR evaluation of AgNDs in Ti plate-based two-electrode configured flow-type electrochemical reactor. a Schematic illustration of two-electrode configured flow-type electrochemical reactor and photographs of assembled reactor and individual cell components. $\mathbf{b}$ LSV curves of Ti plate-based two-electrode flow-type electrochemical reactor with and without $\mathrm{AgNDs}$ incorporation in $\mathrm{Ar}$ - and $\mathrm{N}_{2}$-saturated $0.1 \mathrm{M} \mathrm{Na} \mathrm{SO}_{4}$ solutions ( $\mathrm{pH}=10.5$ ). c The dependence of $\mathrm{NH}_{3}$ yield rate and faradaic efficiency of AgNDs catalyst on the cell voltages in $\mathrm{N}_{2}$-saturated $0.1 \mathrm{M} \mathrm{Na}_{2} \mathrm{SO}_{4}$ electrolyte $(\mathrm{pH}=10.5)$. The error bars correspond to the standard deviations of three independent measurements.

reactors are very favorable for improving the NRR performance due to efficient mass transport and high coverage of $\mathrm{N}_{2}$ on the catalyst $^{31,58,59}$. In this work, a Ti plate-based two-electrode configured flow-type electrochemical reactor was therefore developed to evaluate the AgNDs' NRR performance (Fig. 3a), which should be very suitable for high-efficient utilization of aqueous AgNDs catalyst. During NRR measurements, two Ti plates with "S-type" channel patterns were separated by the Nafion 117 membrane, moreover, a slice of $\mathrm{Ti}$ mesh and carbon cloth (CC) was respectively placed in cathodic compartment and anodic compartment to decrease the excessive current directly caused from the Ti plate current collector to damage Nafion 117 membrane (Fig. 3a). In the cathode side, $\mathrm{N}_{2}$-saturated $0.1 \mathrm{M} \mathrm{Na}_{2} \mathrm{SO}_{4}$ solution with AgNDs incorporation was circulated through the cathodic compartment and returned back to the reservoir with a flow rate of $10 \mathrm{~mL} \mathrm{~min}-1$ under the help of peristaltic pump, while the reaction on anode was conducted at the same conditions without AgNDs incorporation. The purification of feeding gases strictly follows the reported procedure ${ }^{45,46}$. The LSV curves obtained in this two electrode configured flow-type electrochemical cell (Fig. 3b) indicate that the introduction of AgNDs in electrolyte can dramatically improve the NRR activity. Subsequently, we performed the chronoamperometric tests to investigate the effect of applied voltage on $\mathrm{NH}_{3}$ yield rate $\left(\mathrm{R}_{\mathrm{NH} 3}\right)$ and faradaic efficiency (FE) in this flow-type electrochemical cell.
The experimental results show that $\mathrm{NH}_{3}$ product can be detected in both cathodic and anodic compartments (undetectable in the tail gas absorbers), consistent with the results obtained in threeelectrode system (Supplementary Fig. 23a, b). Figure 3c shows the dependence of $\mathrm{R}_{\mathrm{NH} 3}$ and $\mathrm{FE}$ on the applied cell voltage in $\mathrm{N}_{2}-$ saturated $0.1 \mathrm{M} \mathrm{Na}_{2} \mathrm{SO}_{4}$ solution $(\mathrm{pH}=10.5)$ with AgNDs incorporation for $1 \mathrm{~h}$ NRR. The corresponding chronoamperometric curves are shown in Supplementary Fig. 23c. It can be seen that the highest $\mathrm{FE}$ of $15.1 \pm 0.6 \%$ can be obtained at an voltage of $-1.5 \mathrm{~V}$, then decreased at more negative voltage. The largest $\mathrm{R}_{\mathrm{NH} 3}$ is achieved to be $804.5 \pm 30.6 \mu \mathrm{g} \mathrm{h}^{-1} \mathrm{mg}_{\mathrm{Ag}}{ }^{-1}$ with a FE of $8.2 \pm 0.5 \%$ at $-1.8 \mathrm{~V}$. Obviously, the obtained $\mathrm{NH}_{3}$ yield rate in this flow-type electrochemical cell is higher than that from the three-electrode configured system, demonstrating the superiority of aqueous AgNDs-incorporated flow-type reactor.

\section{Discussion}

The above experimental results have illustrated that it is very feasible for high-efficiency electrocatalytic NRR to $\mathrm{NH}_{3}$ utilizing AgNDs introduced three-electrode and two-electrode electrochemical systems. Even so, the faradaic efficiencies of these reaction systems are not very high, and the NRR active mechanism on AgNDs catalyst needs to be clarified in this work. 
Improvement of NRR performance. Based on Fig. 2a, the AgNDs introduction into Ar- or $\mathrm{N}_{2}$-saturated electrolyte results in significantly improved cathodic current in the three-electrode configured electrocatalysis system using metallic Ti mesh as the current collector. The majority of the enhanced cathodic current is primarily originated from the superior hydrogen evolution reaction (HER) of AgNDs ${ }^{16,60}$ on metallic Ti mesh with high electrical conductivity, which results in a decreased faradaic efficiency (FE) of electrocatalytic NRR. To improve the FE of $\mathrm{NRR}$ with high $\mathrm{NH}_{3}$ yield, we speculated that the modification of a metal oxide layer on metallic Ti mesh could be an effective solution to decrease the cathodic current and thus the competitive HER process. The modified metal oxide layer can not only effectively reduce the cathodic current of metallic Ti mesh during AgNDs-incorporated NRR, but also possibly serve as the electrocatalyst providing catalytic active sites for enhanced NRR performance. For this, we fabricated oxygen vacancies-rich $\mathrm{TiO}_{2}$ modified metallic Ti mesh (denoted as $\mathrm{O}_{\mathrm{v}}-\mathrm{TiO}_{2} / \mathrm{Ti}$, see Experimental Section) as the current collector for NRR evaluation. The $\mathrm{X}$-ray diffraction (XRD) patterns (Supplementary Fig. 24) of $\mathrm{O}_{\mathrm{v}^{-}}$ $\mathrm{TiO}_{2} / \mathrm{Ti}$ show that the modified $\mathrm{TiO}_{2}$ on metallic Ti mesh is anatase phase (JCPDS No. $21-1272$ ). The scanning electron microscopy (SEM) images of pristine metallic Ti mesh and $\mathrm{O}_{\mathrm{v}^{-}}$ $\mathrm{TiO}_{2} / \mathrm{Ti}$ samples indicate that no obvious nanostructures can be observed for pristine Ti mesh (Supplementary Fig. 25a-c), while rougher surface structure consisted of nanosheets is clearly observable (Supplementary Fig. 25d-f) for $\mathrm{O}_{\mathrm{v}}-\mathrm{TiO}_{2} / \mathrm{Ti}$. The TEM characterization was further used to precisely analyze the fabricated $\mathrm{TiO}_{2}$ nanosheet structure. As shown in Supplementary Fig. 26, nanosheet structure is obviously dominant and the lattice spacing of $0.352 \mathrm{~nm}$ of an individual nanosheet in HRTEM image is corresponding to the (101) plane of anatase $\mathrm{TiO}_{2}$. Interestingly, it was found that there are some disordered layers on the edge of $\mathrm{TiO}_{2}$ nanosheet, possibly owing to the introduction of rich oxygen vacancies ${ }^{61}$. This can be further verified by the electron paramagnetic resonance (EPR) spectra (Supplementary Fig. 27), in where a stronger signal peak at around $\mathrm{g}=2.007$ is primarily originated from the generated rich oxygen vacancies in $\mathrm{TiO}_{2}$ nanosheets of $\mathrm{O}_{\mathrm{v}}-\mathrm{TiO}_{2} / \mathrm{Ti}$. Recently, our and other groups have demonstrated that oxygen vacancies in metal oxides catalysts can be used as the catalytic active sites for $\mathrm{N}_{2}$ adsorption, activation and hydrogenation ${ }^{55,61-63}$. In this work, $\mathrm{O}_{\mathrm{v}}-\mathrm{TiO}_{2} / \mathrm{Ti}$ can concurrently serve as the current collector and NRR electrocatalyst bifunctionality. As expected, in comparison with metallic $\mathrm{Ti}$ current collector (Fig. 2a), the electrocatalysis system using $\mathrm{O}_{\mathrm{v}}$ $\mathrm{TiO}_{2} / \mathrm{Ti}$ exhibits significantly decreased cathodic current in Arand $\mathrm{N}_{2}$-saturated $\mathrm{Na}_{2} \mathrm{SO}_{4}$ electrolyte with or without AgNDs incorporation (Fig. 4a). Moreover, the $\mathrm{O}_{\mathrm{v}}-\mathrm{TiO}_{2} / \mathrm{Ti}$ shows good electrocatalytic NRR activity (Fig. 4a) in $\mathrm{N}_{2}$-saturated electrolyte. Figure $4 \mathrm{~b}$ displays the dependence of $\mathrm{NH}_{3}$ yield (normalized to the yielded $\mathrm{NH}_{3}$ concentration in cathodic compartment with $50 \mathrm{~mL}$ of electrolyte) and faradaic efficiency (FE) on the applied potential in the non-loading electrocatalysis system using $\mathrm{O}_{\mathrm{v}}-\mathrm{TiO}_{2} / \mathrm{Ti}$ current collector. The corresponding UV-Vis absorption spectra and chronoamperometric curves are shown in Supplementary Fig. 28. As illustrated, the highest FE can be
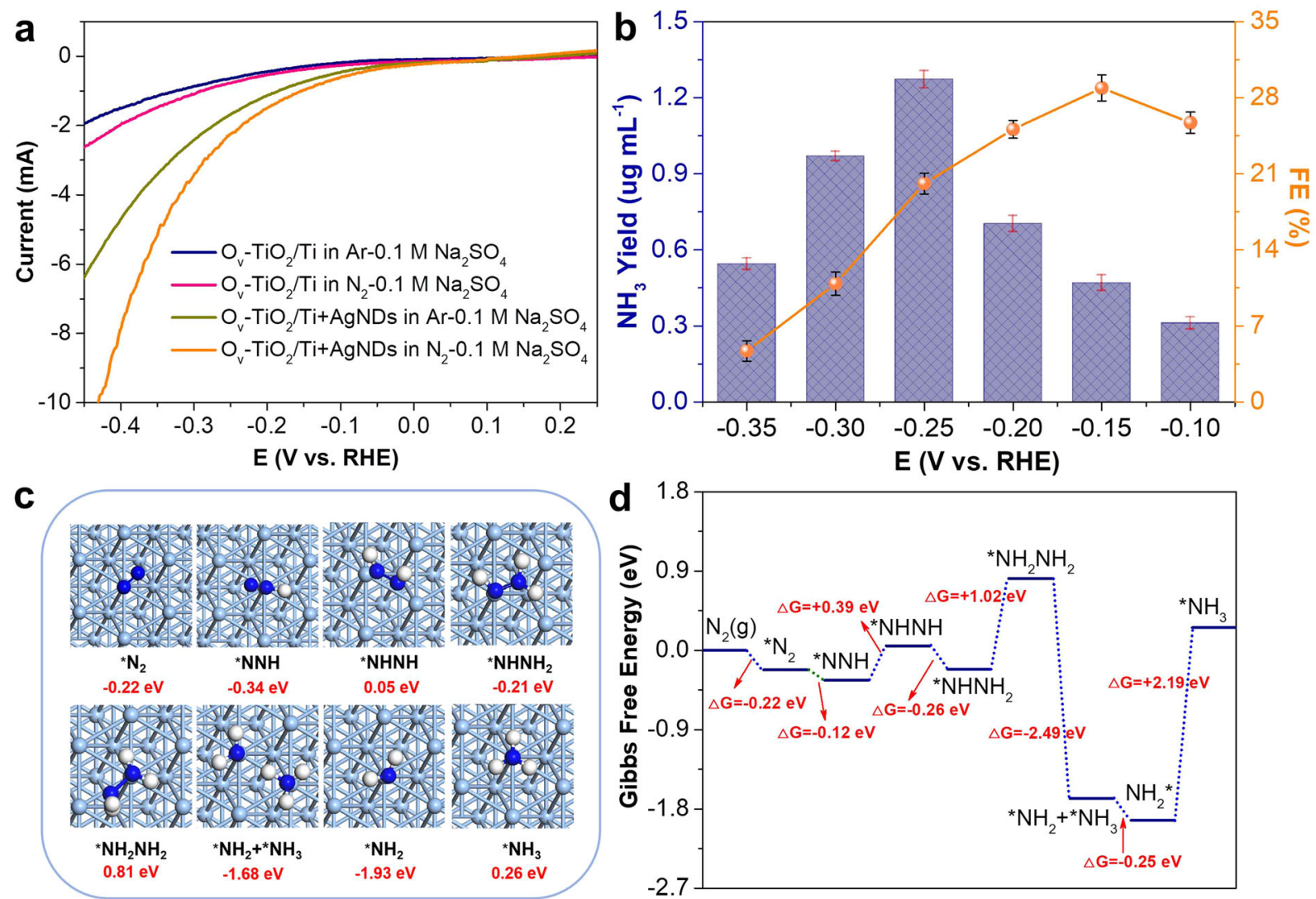

\section{Reaction Coordinate}

Fig. 4 Improvement of NRR performance and NRR active mechanism of AgNDs. a LSV curves of $\mathrm{O}_{\mathrm{v}}-\mathrm{TiO}_{2} / \mathrm{Ti}$ with and without AgNDs incorporation in Ar- and $\mathrm{N}_{2}$-saturated $0.1 \mathrm{M} \mathrm{Na}_{2} \mathrm{SO}_{4}$ solutions $(\mathrm{pH}=10.5)$. b The dependence of $\mathrm{NH}_{3}$ yield and faradaic efficiency of AgNDs catalyst on the applied potential using $\mathrm{O}_{\mathrm{v}}-\mathrm{TiO}_{2} / \mathrm{Ti}$ current collector. The error bars correspond to the standard deviations of three independent measurements. c The top view of the optimized structures of $\mathrm{Ag}$ (111) plane along the lowest energy NRR reaction pathway for $\mathrm{N}_{2}$ conversion into $\mathrm{NH}_{3}$ ( $\mathrm{Ag}$ : cyan, $\mathrm{N}$ : blue, and $\mathrm{H}$ : white). d Free-energy diagram of the $\mathrm{N}_{2}$ reduction reaction at the optimized $\mathrm{Ag}$ (111) plane. 
obtained to be $28.9 \pm 1.2 \%$ at $-0.15 \mathrm{~V}$ (vs. RHE) with $1 \mathrm{~h}$ $\mathrm{NRR}$, while the largest $\mathrm{NH}_{3}$ yield can be achieved to be $1.27 \pm$ $0.03 \mu \mathrm{g} \mathrm{mL}^{-1}$ with a FE of $20.1 \pm 0.9 \%$ at $-0.25 \mathrm{~V}$ (vs. RHE) for $1 \mathrm{~h} \mathrm{NRR}$, which includes two part contributions from $\mathrm{O}_{\mathrm{v}}-\mathrm{TiO}_{2} / \mathrm{Ti}$ and AgNDs catalyzed NRR processes. For $\mathrm{O}_{\mathrm{v}}-\mathrm{TiO}_{2} / \mathrm{Ti}$ catalyzed NRR without AgNDs, the $\mathrm{NH}_{3}$ yield can be obtained to be $0.37 \pm$ $0.01 \mu \mathrm{g} \mathrm{mL}^{-1}$ with a FE of $10.1 \pm 0.8 \%$ at $-0.25 \mathrm{~V}$ (vs. RHE) for $1 \mathrm{~h}$ NRR (Supplementary Fig. 29). Apparently, the introduction of AgNDs results in significantly improved NRR performance using $\mathrm{O}_{\mathrm{v}}-\mathrm{TiO}_{2} / \mathrm{Ti}$ current collector with high stability (Supplementary Fig. 30), primarily owing to superior NRR activity of AgNDs combined with the contribution from $\mathrm{O}_{\mathrm{v}}-\mathrm{TiO}_{2} / \mathrm{Ti}$ catalyzed NRR. In addition, the $\mathrm{NH}_{3}$ yield and $\mathrm{FE}$ in the non-loading electrocatalysis system using $\mathrm{O}_{\mathrm{v}}-\mathrm{TiO}_{2} / \mathrm{Ti}$ current collector are almost 1.4 and 2 times of those achieved from the electrocatalysis system using metallic Ti mesh current collector $\left(\mathrm{NH}_{3}\right.$ yield of $0.90 \pm 0.03 \mu \mathrm{g} \mathrm{mL}^{-1}$ and FE of $10.1 \pm 0.7 \%$ at $-0.25 \mathrm{~V}$ vs. RHE), demonstrating that the strategy of metallic Ti mesh modification is feasible for further enhancing the electrocatalytic NRR performance.

NRR active mechanism. A recent work has demonstrated that the catalytic activity of Ag nanoparticles is dramatically enhanced with decreasing the nanoparticle size to $\sim 5 \mathrm{~nm}^{12}$. In addition, the theoretical and experimental results have revealed that the (111) planes exposed Ag nanostructures possess high electrocatalytic activities $14,16,27,28$. In this work, the fabricated aqueous Ag nanodots with small sizes exhibit highly exposed (111) crystalline planes (Fig. 1b, Supplementary Fig. 12), we therefore constructed the optimized structure model of $\mathrm{Ag}(111)$ plane (Supplementary Fig. 31) to investigate the NRR active mechanism of AgNDs by the density functional theory (DFT) calculations. Firstly, we optimized the adsorption configurations of $\mathrm{N}_{2}$ on the $\operatorname{Ag}(111)$ plane. As shown in Supplementary Fig. 32, an end-on adsorption configuration with a certain inclination was found to be more thermodynamically favorable for $\mathrm{N}_{2}$ adsorption and activation. The DFT calculations results indicate that N-N bond can be elongated to $1.114 \AA$ for the adsorbed $\mathrm{N}_{2}$ on $\mathrm{Ag}(111)$ plane from $1.090 \AA$ for an isolated $\mathrm{N}_{2}$ molecule, suggesting the possibility of the first hydrogenation step in the next step. Figure $4 \mathrm{c}$ presents the top view of the optimized structures of $\mathrm{Ag}(111)$ surface along the lowest energy NRR reaction pathway for $\mathrm{N}_{2}$ conversion to $\mathrm{NH}_{3}$. After the first hydrogenation of $\mathrm{N}_{2}$, the $\mathrm{N}-\mathrm{N}$ bond is elongated from $1.114 \AA$ of ${ }^{*} \mathrm{~N}_{2}$ to $1.180 \AA$ of ${ }^{*} \mathrm{~N}_{2} \mathrm{H}$. The N-N bond length can be further elongated to $1.260 \AA$ of $* \mathrm{NHNH}$, $1.358 \AA$ of $* \mathrm{NHNH}_{2}$ and $1.431 \AA$ of ${ }^{*} \mathrm{NH}_{2} \mathrm{NH}_{2}$ by an alternative hydrogenation process. At last, the $\mathrm{N} \equiv \mathrm{N}$ triple bond breaks to form the first $\mathrm{NH}_{3}$ molecule. Based on our theoretical calculations, the $1^{\text {st }}, 3^{\text {rd }}, 5^{\text {th }}$ and $6^{\text {th }}$ hydrogenation steps are exothermic processes and the energies of $2^{\text {nd }}, 4^{\text {th }}$ and $7^{\text {th }}$ (second $\mathrm{NH}_{3}$ generation) hydrogenation steps are up-hill (Fig. 4d). Moreover, the formation of second $\mathrm{NH}_{3}$ molecule ( $7^{\text {th }}$ hydrogenation step) can be identified as the rate determining step with a needed energy $(\triangle \mathrm{G})$ of $2.19 \mathrm{eV}$. The above theoretical calculations results indicate that the $\operatorname{Ag}(111)$ surface is capable of adsorbing and activating $\mathrm{N}_{2}$ molecules, thus affording excellent NRR performance.

In summary, we demonstrated the feasibility of using $\mathrm{Ag}$ nanodots catalyst dispersed in aqueous solution in non-loading electrocatalysis system for high-efficiency electrocatalytic $\mathrm{N}_{2}$ reduction reaction (NRR) to $\mathrm{NH}_{3}$. Such electrochemical system can take full advantage of the catalytic active sites provided by $\mathrm{Ag}$ nanodots with highly exposed (111) planes for $\mathrm{N}_{2}$ adsorption and activation, and the NRR performance can be further enhanced by simple modification of the metallic Ti mesh current collector. Using the fabricated aqueous Ag nanodots catalyst, a twoelectrode configured flow-type electrochemical reactor has been developed and evaluated for the NRR, demonstrating great potential for $\mathrm{NH}_{3}$ production. Our work provides a significant guidance on designing high-efficiency electrocatalysts and electrocatalysis systems for ambient electrosynthesis of $\mathrm{NH}_{3}$.

\section{Methods}

Fabrication of Ag nanodots (AgNDs) solution. Aqueous AgNDs solution was synthesized by a facile one-step laser-ablation technique. In a typical synthesis, a polished silver metal plate $(99.99 \%$ purity) was fixed on a bracket in a vessel containing $17 \mathrm{~mL}$ of deionized water under continuously stirring $(10 \mathrm{rpm})$ by an amotorized tunable stage (WNSC 400). The deionized water level above the silver target surface was $\sim 10 \mathrm{~mm}$. The silver plate in deionized water was subsequently irradiated for $30 \mathrm{~min}$ by a focused laser ( $532 \mathrm{~nm} \mathrm{Nd:YAG} \mathrm{pulsed} \mathrm{laser)} \mathrm{with} 8 \mathrm{~ns}$ pulse duration, $100 \mathrm{~mJ}$ power energy per pulse and spot size of $1.0 \mathrm{~mm}$ in diameter in Ar atmosphere. Finally, the AgNDs solution was obtained with a color of bright yellow. $\mathrm{Ag}_{2} \mathrm{O}$ nanoparticles ( $\mathrm{Ag}_{2} \mathrm{ONPs}$ ) solution was fabricated from the $\mathrm{O}_{2}$-saturated AgNDs solution at $50^{\circ} \mathrm{C}$ for $1 \mathrm{~h}$.

Fabrication of Ag nanoparticles (AgNPs) solution. AgNPs solution was synthesized employing the similar progress with AgNDs solution fabrication using the laser-ablation technique. In a typical synthesis, the polished silver metal plate was ablated in $15 \mathrm{~mL}$ of deionized water with a focused laser at $1064 \mathrm{~nm}, 80 \mathrm{~mJ}$ power energy per pulse and spot size of $1.5 \mathrm{~mm}$ in diameter under Ar atmosphere to obtain AgNPs solution.

Fabrication of oxygen vacancies-rich $\mathrm{TiO}_{2}$ nanosheets modified metallic $\mathrm{Ti}$ mesh. In a typical synthesis, metallic titanium $(\mathrm{Ti})$ mesh $\left(4.0 \times 4.0 \mathrm{~cm}^{2}\right)$ was placed in a Teflon-lined stainless steel autoclave $(50 \mathrm{~mL}$, Anhui Kemi Machinery Technology Co., Ltd) with $30 \mathrm{~mL}$ of $5.0 \mathrm{M} \mathrm{NaOH}$ solution for hydrothermal reaction at $180^{\circ} \mathrm{C}$ with $14 \mathrm{~h}$. After the autoclave was cooled down to room temperature, the obtained samples were collected and washed with deionized water and ethanol for several times, and dried in an oven at $60^{\circ} \mathrm{C}$ for $20 \mathrm{~min}$. Then the samples were immersed into $0.5 \mathrm{M} \mathrm{HCl}$ solution for $2 \mathrm{~h}$ to exchange $\mathrm{Na}^{+}$with $\mathrm{H}^{+}$. Finally, the oxygen vacancies-rich $\mathrm{TiO}_{2}$ nanosheets modified metallic Ti mesh $\left(\mathrm{O}_{\mathrm{v}}-\mathrm{TiO}_{2} / \mathrm{Ti}\right)$ was achieved by thermal treatment of the hydrothermally obtained sample at $700{ }^{\circ} \mathrm{C}$ in $\mathrm{H}_{2} / \mathrm{Ar}$ atmosphere for $1 \mathrm{~h}$ with a heating rate of $5{ }^{\circ} \mathrm{C} \mathrm{min}^{-1}$.

Characterization. The morphologies and precise structures of the samples were determined by the field emission scanning electron microscopy (FESEM, Quanta 200FEG) and transmission electron microscopy (TEM, JEOL JEM-2010 and Tecnai TF20 TMP). The X-ray photoelectron spectroscopy (XPS) analysis of the samples was performed on an ESCA LAB250 X-ray photoelectron spectrometer (Thermo, America) equipped with $\mathrm{A} 1 \mathrm{Ka}$ as the X-ray source. The Raman spectra of the samples were recorded on a RXN1-785 Raman spectrometer (Analytik Jena AG, excited wavelength of $785 \mathrm{~nm}$ ). For in situ Raman tests, the experiments were performed on RXN1-785 Raman spectrometer connected with CHI660D electrochemical workstation. A quartz-made electrochemical cell containing AgNDs nanodots electrocatalyst dispersed in $0.1 \mathrm{M} \mathrm{Na}_{2} \mathrm{SO}_{4}$ solution $(\mathrm{pH}=10.5)$ was placed in the front of Raman fiber optic probe. Potentiostatic tests were conducted following the same way in long time durability test at $-0.25 \mathrm{~V}$ (vs. RHE) for $5 \mathrm{~h}$ NRR and Raman spectra with temporal resolution of $30 \mathrm{~s}$ was adopted to achieve the in situ monitoring. The amount of Ag nanodots in solution was analyzed by the inductively coupled plasma optical emission spectroscopy (ICP-OES 6300, Thermo Fisher Scientific). The $\mathrm{N}_{2}$ temperature-programmed desorption $\left(\mathrm{N}_{2}-\mathrm{TPD}\right)$ experiments were conducted on a Quantachrome ChemBET Pulsar TPR/TPD. The Zeta potential of the Ag nanodots solution was measured using JS94H2 microelectrophoresis instrument (Shanghai Zhongchen, China). The room temperature electron paramagnetic resonance (EPR) spectra were recorded on the Steady High Magnetic Field Facilities, High Magnetic Field Laboratory, CAS.

Electrochemical measurements. All electrochemical measurements were performed at room temperature on CHI660D (CH Instruments, Inc., Shanghai, China) electrochemical workstation using a three-electrode configured twocompartment electrochemical cell (ZY-CD02A, Chintek Instrument \& Equipment Co., Ltd. China). In the non-loading electrocatalysis system, metallic Ti mesh or $\mathrm{O}_{\mathrm{v}}-\mathrm{TiO}_{2} / \mathrm{Ti}\left(4.0 \times 4.0 \mathrm{~cm}^{2}\right)$ was used as the current collector, and commercial carbon cloth and $\mathrm{Ag} / \mathrm{AgCl}$ (saturated $\mathrm{KCl}$ electrolyte) were used as the counter electrode and reference electrode, respectively. $\mathrm{Na}_{2} \mathrm{SO}_{4}$ powder was thermally treated under $5 \%$ Ar stream before preparation of $0.1 \mathrm{M} \mathrm{Na}_{2} \mathrm{SO}_{4}$ solution. The synthesized AgNDs solution $(3.0 \mathrm{~mL}, 0.075 \mathrm{mg}$, $\mathrm{pH}=9.5)$ as the electrocatalyst was dispersed into Ar-saturated $0.1 \mathrm{M} \mathrm{Na}_{2} \mathrm{SO}_{4}$ solution $(47 \mathrm{~mL})$ in the cathodic compartment for NRR measurements. The $\mathrm{pH}$ value of $0.1 \mathrm{M} \mathrm{Na}_{2} \mathrm{SO}_{4}$ solution containing the synthesized AgNDs 
solution with different concentrations were all adjusted to 10.5. For comparison, the conventional catalyst-loading electrocatalysis experiments were also performed using AgNDs (or AgNPs, $\mathrm{Ag}_{2} \mathrm{ONPs}$ ) coated on commercial carbon cloth (CC) as the working electrode, commercial CC as the counter electrode, and $\mathrm{Ag} / \mathrm{AgCl}$ (saturated $\mathrm{KCl}$ electrolyte) as the reference electrode. For the preparation of working electrode, $3.0 \mathrm{~mL}$ of AgNDs (or AgNPs, $\mathrm{Ag}_{2} \mathrm{ONPs}$ ) solution containing $5.0 \mathrm{wt} . \%$ Nafion solution was first ultrasonically treated for 30 min to form a homogeneous catalyst ink, and then the catalyst ink was casted on a clean carbon cloth $\left(1.0 \times 1.0 \mathrm{~cm}^{2}\right)$ with a catalyst loading amount of $\sim 0.075 \mathrm{mg} \mathrm{cm}^{-2}$ and subsequently dried at $60^{\circ} \mathrm{C}$ for $2 \mathrm{~h}$ in vacuum. Both of the cathodic chamber and anodic chamber contained $50 \mathrm{~mL}$ of $0.1 \mathrm{M} \mathrm{Na}_{2} \mathrm{SO}_{4}$ solution $(\mathrm{pH}=10.5)$. In this work, all measured electrochemical potentials were calibrated to be vs. reversible hydrogen electrode (RHE) by the following equation:

$$
E(\mathrm{~V} v \mathrm{RHE})=E(\mathrm{Vvs} . \mathrm{Ag} / \mathrm{AgCl})+0.059 \times \mathrm{pH}+0.197
$$

where $E(\mathrm{~V}$ vs. $\mathrm{RHE})$ is the converted potential $(\mathrm{V})$ vs. RHE, $E(\mathrm{~V}$ vs. $\mathrm{Ag} / \mathrm{AgCl})$ is the experimentally measured potential against $\mathrm{Ag} / \mathrm{AgCl}$ reference electrode, 0.197 is the value of standard potential for the $\mathrm{Ag} / \mathrm{AgCl}$ reference electrode (saturated $\mathrm{KCl}$ electrolyte) at $25^{\circ} \mathrm{C}$.

For the two-electrode system NRR evaluation, a metallic Ti plate-based flowtype electrochemical reactor was designed and developed, and Nafion 117 membrane was sandwiched by a piece of carbon cloth $\left(10 \times 10 \mathrm{~cm}^{2}\right)$ and metallic Ti mesh $\left(10 \times 10 \mathrm{~cm}^{2}\right)$, and then all clamped together using two metallic Ti plates with S-shaped channel served as the current collectors. For a typical electrochemical test in this flow-type cell, $50 \mathrm{~mL}$ of $0.1 \mathrm{M} \mathrm{Na}_{2} \mathrm{SO}_{4}$ solution $(\mathrm{pH}=$ 10.5) with and without $0.003 \mathrm{mg} \mathrm{mL}^{-1} \mathrm{AgNDs}$ was respectively flowed through the cathodic cell and anodic cell, and then returned back to the reservoir using multichannel peristaltic pump at a flow rate of $10 \mathrm{~mL} \mathrm{~min}^{-1}$. The electrolyte solutions after NRR tests were extracted in the reservoir for further identification and quantification.

The polarization curves during electrochemical measurements were recorded with a scan rate of $5.0 \mathrm{mV} \mathrm{s}^{-1}$ at room temperature and all polarization curves were obtained at the steady-state ones after several cycles. For the non-loading electrocatalysis measurements and two-electrode flow-type cell system, the potentiostatic tests were conducted in $\mathrm{N}_{2}$-saturated $0.1 \mathrm{M} \mathrm{Na}_{2} \mathrm{SO}_{4}$ solution $(\mathrm{pH}=$ 10.5) containing AgNDs with continuously bubbling $\mathrm{N}_{2}$ at a flow rate of $\sim 15 \mathrm{~mL}$ $\min ^{-1}$ under adequately stirring at different potentials for $1 \mathrm{~h}$. All NRR experiments were carried out at room temperature and atmospheric pressure. Prior to each measurement, $\mathrm{N}_{2}$ or Ar feeding gas was first pre-purged by the $\mathrm{Cu}-\mathrm{Fe}-\mathrm{Al}$ catalyst, $\mathrm{CrO}_{3}$ column, $1.0 \mathrm{mM} \mathrm{H}_{2} \mathrm{SO}_{4}$ solution $(20 \mathrm{~mL})$ and distilled water $(20 \mathrm{~mL})$ to eliminate the potential $\mathrm{NO}_{\mathrm{x}}$ and $\mathrm{NH}_{3}$ contaminants based on the previously reported protocols ${ }^{45,46}$.

Determination of ammonia. The produced ammonia during NRR was spectrophotometrically detected by the indophenol blue method on a UV-Vis 2700 spectrophotometer (Shimadzu, Japan). In detail, $5.0 \mathrm{~mL}$ of sample was diluted with $5.0 \mathrm{~mL}$ of deionized water. Subsequently, $500 \mu \mathrm{L}$ of $0.55 \mathrm{M} \mathrm{NaOH}$ coloring solution (5.0 wt.\% salicylic acid and $5.0 \mathrm{wt} . \%$ sodium citrate), $100 \mu \mathrm{L}$ of catalyst solution $\left(0.1 \mathrm{~g} \mathrm{Na}_{2}\left[\mathrm{Fe}(\mathrm{CN})_{5} \mathrm{NO}\right] \cdot 2 \mathrm{H}_{2} \mathrm{O}\right.$ diluted to $10 \mathrm{~mL}$ with deionized water), $100 \mu \mathrm{L}$ of oxidizing solution (sodium hypochlorite $(\rho \mathrm{Cl}=4 \sim 4.9)$ and $0.75 \mathrm{M}$ sodium hydroxide) were added respectively to the measured sample solution. After standing at room temperature for $1 \mathrm{~h}$, the UV-Vis absorption spectrum was measured at a wavelength of $697.5 \mathrm{~nm}$. The concentrationabsorbance curves were calibrated using standard $\mathrm{NH}_{4} \mathrm{Cl}$ solutions with a series of concentrations in $0.1 \mathrm{M} \mathrm{Na}_{2} \mathrm{SO}_{4}$ solution $(\mathrm{pH}=10.5)$ with and without AgNDs incorporation and the obtained calibration curve $(y=0.013+0.811 x$, $\left.\mathrm{R}^{2}=0.999\right)$ was used to calculate the produced ammonia concentration.

Determination of hydrazine. The produced hydrazine concentration was determined by the method of Watt and Chrisp. In detail, a mixture of para (dimethylamino) benzaldehyde $(5.99 \mathrm{~g}), \mathrm{HCl}$ (concentrated, $30 \mathrm{~mL}$ ) and ethanol $(300 \mathrm{~mL}$ ) were used as the color reagent. $100 \mu \mathrm{L}$ of sample was acidized with 10 $\mathrm{mL}$ of $1.0 \mathrm{M} \mathrm{HCl}$ solution, and then $5.0 \mathrm{~mL}$ of color reagent added to the above sample solution with rapid stirring for several times. After standing at room temperature for $20 \mathrm{~min}$, the UV-Vis absorption spectrum was obtained at a wavelength of $455 \mathrm{~nm}$. The concentration-absorbance curves were calibrated using standard $\mathrm{N}_{2} \mathrm{H}_{4} \cdot \mathrm{H}_{2} \mathrm{O}$ solutions with a series of concentrations in $0.1 \mathrm{M}$ $\mathrm{Na}_{2} \mathrm{SO}_{4}$ solution $(\mathrm{pH}=10.5)$ with and without AgNDs incorporation, and the obtained calibration curve $\left(y=0.826 x+0.007, R^{2}=0.999\right)$ was used to calculate the ammonia concentration.

Calculations of $\mathbf{N H}_{3}$ yield rate $\left(\mathbf{R}_{\mathbf{N H} 3}\right)$ and faradaic efficiency (FE). The calculation of $\mathrm{NH}_{3}$ yield rate $\left(R_{\mathrm{NH}}\right)$ is as following equation:

$$
R_{\mathrm{NH}_{3}}\left(\mu g \mathrm{~h}^{-1 \mathrm{mg}_{\text {cat. }}^{-1}}\right)=\frac{\chi\left(\mu g \mathrm{~mL}^{-1}\right) \times V(\mathrm{~mL})}{t(\mathrm{~h}) \times m\left(\mathrm{mg}^{-1}\right)}
$$

The calculation of faradaic efficiency (FE) is as following equation:

$$
F E(\%)=\frac{3 \times \chi\left(\mu g \mathrm{~mL}^{-1}\right) \times V(\mathrm{~mL}) \times 10^{-6} \times F}{17 \times Q} \times 100 \%
$$

where $\chi\left(\mu \mathrm{gL}^{-1}\right)$ is the produced ammonia concentration; $V(\mathrm{~mL})$ is the electrolyte solution volume; $m$ is the catalyst weight; $t(\mathrm{~s})$ is the reaction time; $F$ is the faradaic constant (96485.34); $Q$ is the total charge passed through the electrode during NRR.

Isotope labeling experiments. The ${ }^{14} \mathrm{~N}$ and ${ }^{15} \mathrm{~N}$ isotopic labeling experiments were conducted using ${ }^{14} \mathrm{~N}_{2}$ and ${ }^{15} \mathrm{~N}_{2}$ as the feeding gases (99\% enrichment of ${ }^{15} \mathrm{~N}$ in ${ }^{15} \mathrm{~N}_{2}$ feeding gas, Supplied by Hefei Ninte Gas Management Co., LTD). Prior to use, ${ }^{14} \mathrm{~N}_{2}$ and ${ }^{15} \mathrm{~N}_{2}$ feeding gases were pre-purged by the $\mathrm{Cu}-\mathrm{Fe}-\mathrm{Al}$ catalyst, $\mathrm{CrO}_{3}$ column, $1.0 \mathrm{mM} \mathrm{H}_{2} \mathrm{SO}_{4}$ solution $(20 \mathrm{~mL})$ and distilled water $(20 \mathrm{~mL})$ to eliminate the potential $\mathrm{NO}_{\mathrm{x}}$ and $\mathrm{NH}_{3}$ contaminants based on the reported protocols $s^{45,46}$. After the electrochemical reaction at $-0.25 \mathrm{~V}$ (vs. RHE) for $1 \mathrm{~h}$, the reaction solution of both cathodic and anodic chambers $(100 \mathrm{~mL})$ was concentrated to 2.0 $\mathrm{mL}$ at $80^{\circ} \mathrm{C}$. Then, $1.0 \mathrm{~mL}$ of above solution mixed with $0.2 \mathrm{~mL}$ of $\mathrm{D}_{2} \mathrm{O}$ was used for ${ }^{1} \mathrm{H}$ NMR spectroscopy measurement (Bruker AVANCE AV III 400). The ${ }^{1} \mathrm{H}$ NMR analysis and calibration curve construction were carried out in accordance with the reported method.

Computational methods. To investigate the $\mathrm{N}_{2}$ reduction reaction (NRR) process on the Ag (111) surface, the density functional theory (DFT) calculations were carried out by Viena ab initio software package (VASP) ${ }^{64,65}$. The Projector Augmented Wave (PAW) potentials were used for the treatment of core electrons ${ }^{66}$. The generalized gradient approximation (GGA) with the Perdew-Burke-Ernzerh (PBE) function was used for description of the electron exchange correlation interactions $s^{67}$. Van der Waals interactions were described via DFT-D3 correlation 68 . A $2 \times 2 \times 2$ supercell slab model was built with the lattice parameters of $a=$ $11.64, b=11.64 \AA$ and a vacuum of $15 \AA$ was added in the $z$ direction. The convergence criterion of geometry relaxation was $0.01 \mathrm{eV}^{-1}$ in forceon each atom. The energy cutoff for plane wave-basis was set to $500 \mathrm{eV}$. The $K$ points were sampled with $3 \times 3 \times 1$ by Monkhorst-Pack method. The free energies of the NRR steps were calculated by $\Delta G=\Delta E_{\text {ads }}+\Delta E_{\mathrm{ZPE}}-T \Delta S+\Delta G(U)+\Delta G(p H)$, where $\Delta E_{\text {ads }}$ is the adsorption energy, $\Delta E_{\mathrm{ZPE}}$ is the zero point energy and $S$ is the entropy at $298 \mathrm{~K}$. Considering the applied potential of the NRR reaction, the free energy of each step was calculated by adding the value of $\Delta G(U)=-n e U$, where $U$ is the applied bias, $n$ is the number of electrons involved in the reaction. In our calculations, we used $U=-0.25 \mathrm{~V}$ (vs. RHE). $\Delta G(p H)=-k_{B} T \ln 10 \times p H$, where $k_{B}$ is the Boltzmann constant, and $p H=10.5$ of the used electrolyte. In this study, the entropies of molecules in the gas phase are obtained from the literature ${ }^{69}$.

\section{Data availability}

The authors declare that all the data supporting the findings of this study are available within the article (and Supplementary Information Files), or available from the corresponding author on reasonable request.

Received: 23 September 2020; Accepted: 4 January 2021; Published online: 29 January 2021

\section{References}

1. Chen, J. G. et al. Beyond fossil fuel-driven nitrogen transformations. Science 360, 873 (2018).

2. Chu, S. \& Majumdar, A. Opportunities and challenges for a sustainable energy future. Nature 488, 294 (2012).

3. Falcone, M., Chatelain, L., Scopelliti, R., Živković, I. \& Mazzanti, M. Nitrogen reduction and functionalization by a multimetallic uranium nitride complex. Nature 547, 332 (2017)

4. Légaré, M.-A. et al. Nitrogen fixation and reduction at boron. Science 359, 896 (2018).

5. Wang, L. et al. Greening ammonia toward the solar ammonia refinery. Joule 2, 1055-1074 (2018).

6. Guo, C., Ran, J., Vasileff, A. \& Qiao, S. Z. Rational design of electrocatalysts and photo(electro)catalysts for nitrogen reduction to ammonia $\left(\mathrm{NH}_{3}\right)$ under ambient conditions. Energy Environ. Sci. 11, 45-56 (2018).

7. Shipman, M. A. \& Symes, M. D. Recent progress towards the electrosynthesis of ammonia from sustainable resources. Catal. Today 286, 57-68 (2017).

8. Deng, J., Iñiguez, J. A. \& Liu, C. Electrocatalytic nitrogen reduction at low temperature. Joule 2, 846-856 (2018).

9. Suryanto, B. H. R. et al. Challenges and prospects in the catalysis of electroreduction of nitrogen to ammonia. Nat. Catal. 2, 290-296 (2019). 
10. Wan, Y., Xu, J. \& Lv, R. Heterogeneous electrocatalysts design for nitrogen reduction reaction under ambient conditions. Mater. Today 27, 69-90 (2019).

11. Cui, X., Tang, C. \& Zhang, Q. A review of electrocatalytic reduction of dinitrogen to ammonia under ambient conditions. Adv. Energy Mater. 8, 1800369 (2018).

12. Salehi-Khojin, A. et al. Nanoparticle silver catalysts that show enhanced activity for carbon dioxide electrolysis. J. Phys. Chem. C. 117, 1627-1632 (2013).

13. Yang, X. F. et al. Single-atom catalysts: a new frontier in heterogeneous catalysis. Acc. Chem. Res. 46, 1740-1748 (2013).

14. Back, S., Yeom, M. S. \& Jung, Y. Active sites of Au and Ag nanoparticle catalysts for $\mathrm{CO}_{2}$ electroreduction to CO. ACS Catal. 5, 5089-5096 (2015).

15. Zhang, H., Liu, G., Shi, L. \& Ye, J. Single-atom catalysts: emerging multifunctional materials in heterogeneous catalysis. Adv. Energy Mater. 8, 1701343 (2018).

16. Kang, W. J. et al. Ultrafine Ag nanoparticles as active catalyst for electrocatalytic hydrogen production. ChemCatChem 11, 5976-5981 (2019).

17. Yan, Y. et al. Recent advances on graphene quantum dots: from chemistry and physics to applications. Adv. Mater. 31, 1808283 (2019).

18. Weiss, E. A. Designing the surfaces of semiconductor quantum dots for colloidal photocatalysis. ACS Energy Lett. 2, 1005-1013 (2017).

19. $\mathrm{Wu}, \mathrm{H}$. L. et al. Semiconductor quantum dots: an emerging candidate for $\mathrm{CO}_{2}$ photoreduction. Adv. Mater. 31, 1900709 (2019).

20. Chu, K. et al. Efficient electrocatalytic $\mathrm{N}_{2}$ reduction on $\mathrm{CoO}$ quantum dots. J. Mater. Chem. A 7, 4389-4394 (2019).

21. Wang, F. et al. $\mathrm{CuO} / \mathrm{Graphene}$ nanocomposite for nitrogen reduction reaction. ChemCatChem 11, 1441-1447 (2019).

22. $\mathrm{Chu}, \mathrm{K}$. et al. $\mathrm{NiO}$ nanodots on graphene for efficient electrochemical $\mathrm{N}_{2}$ reduction to $\mathrm{NH}_{3}$. ACS Appl. Energy Mater. 2, 2288-2295 (2019).

23. Liu, Y. P. et al. $\mathrm{ZnO}$ quantum dots coupled with graphene toward electrocatalytic $\mathrm{N}_{2}$ reduction: experimental and DFT investigations. Chem. Eur. J. 25, 11933-11939 (2019).

24. Chu, K. et al. Electronically coupled $\mathrm{SnO}_{2}$ quantum dots and graphene for efficient nitrogen reduction reaction. ACS Appl. Mater. Interfaces 11, 31806-31815 (2019).

25. Cheng, $\mathrm{H}$. et al. Molybdenum carbide nanodots enable efficient electrocatalytic nitrogen fixation under ambient conditions. Adv. Mater. 30 1803694 (2018).

26. Huang, $\mathrm{H}$. et al. Ag nanosheets for efficient electrocatalytic $\mathrm{N}_{2}$ fixation to $\mathrm{NH}_{3}$ under ambient conditions. Chem. Commun. 54, 11427-11430 (2018).

27. Ji, L. et al. Nanostructured bromide-derived Ag film: an efficient electrocatalyst for $\mathrm{N}_{2}$ reduction to $\mathrm{NH}_{3}$ under ambient conditions. Inorg. Chem. 57, 14692-14697 (2018).

28. Gao, W. Y. et al. Morphology-dependent electrocatalytic nitrogen reduction on Ag triangular nanoplates. Chem. Commun. 55, 10705-10708 (2019).

29. Lee, H. K. et al. Favoring the unfavored: selective electrochemical nitrogen fixation using a reticular chemistry approach. Sci. Adv. 4, eaar3208 (2018).

30. $\mathrm{Yu}, \mathrm{H}$. et al. Bimetallic $\mathrm{Ag}_{3} \mathrm{Cu}$ porous networks for ambient electrolysis of nitrogen to ammonia. J. Mater. Chem. A 7, 12526-12531 (2019).

31. Chen, Y. et al. Highly productive electrosynthesis of ammonia by admoleculetargeting single Ag sites. ACS Nano 14, 6938-6946 (2020).

32. Zhang, D. et al. Laser synthesis and processing of colloids: fundamentals and applications. Chem. Rev. 117, 3990-4103 (2017).

33. Zhao, Z. et al. Vertically aligned $\mathrm{MoS}_{2} / \mathrm{Mo}_{2} \mathrm{C}$ hybrid nanosheets grown on carbon paper for efficient electrocatalytic hydrogen evolution. ACS Catal. 7, 7312-7318 (2017).

34. Sun, F. et al. NiFe-based metal-organic framework nanosheets directly supported on nickel foam acting as robust electrodes for electrochemical oxygen evolution reaction. Adv. Energy Mater. 8, 1800584 (2018).

35. Nazemi, M. \& El-Sayed, M. A. The role of oxidation of silver in bimetallic gold-silver nanocages on electrocatalytic activity of nitrogen reduction reaction. J. Phys. Chem. C. 123, 11422-11427 (2019).

36. Wang, M. et al. Over $56.55 \%$ faradaic efficiency of ambient ammonia synthesis enabled by positively shifting the reaction potential. Nat. Commun. 10, 341 (2019).

37. Nazemi, M. \& El-Sayed, M. A. Plasmon-enhanced photo(electro)chemical nitrogen fixation under ambient conditions using visible light responsive hybrid hollow Au- $\mathrm{Ag}_{2} \mathrm{O}$ nanocages. Nano Energy 63, 103886 (2019).

38. Mistry, H. et al. Enhanced carbon dioxide electroreduction to carbon monoxide over defect-rich plasma-activated silver catalysts. Angew. Chem. Int. Ed. 56, 11394-11398 (2017).

39. Wachs, I. E. \& Roberts, C. A. Monitoring surface metal oxide catalytic active sites with raman spectroscopy. Chem. Soc. Rev. 39, 5002-5017 (2010).

40. Ling, X. Y. et al. Alumina-coated Ag nanocrystal monolayers as surfaceenhanced raman spectroscopy platforms for the direct spectroscopic detection of water splitting reaction intermediates. Nano Res. 7, 132-143 (2013).
41. Martina, I. et al. Micro-raman characterisation of silver corrosion products: instrumental set up and reference database. e-Preserv. Sci. 9, 1-8 (2012).

42. Xiao, J., Liu, P., Wang, C. X. \& Yang, G. W. External field-assisted laser ablation in liquid: an efficient strategy for nanocrystal synthesis and nanostructure assembly. Prog. Mater. Sci. 87, 140-220 (2017).

43. Liu, Y. et al. Coupling $\mathrm{Mo}_{2} \mathrm{C}$ with nitrogen-rich nanocarbon leads to efficient hydrogen-evolution electrocatalytic sites. Angew. Chem., Int. Ed. 54, 10752-10757 (2015)

44. Huang, L. B. et al. Self-limited on-site conversion of $\mathrm{MoO}_{3}$ nanodots into vertically aligned ultrasmall monolayer $\mathrm{MoS}_{2}$ for efficient hydrogen evolution. Adv. Energy Mater. 8, 1800734 (2018).

45. Andersen, S. Z. et al. A rigorous electrochemical ammonia synthesis protocol with quantitative isotope measurements. Nature 570, 504-508 (2019).

46. Zhang, S. et al. Electrocatalytically active Fe- $\left(\mathrm{O}-\mathrm{C}_{2}\right)_{4}$ single-Atom sites for efficient reduction of nitrogen to ammonia. Angew. Chem. Int. Ed. 59, 13423-13429 (2020)

47. Wang, J. et al. Ambient ammonia synthesis via palladium-catalyzed electrohydrogenation of dinitrogen at low overpotential. Nat. Commun. 9, 1795 (2018)

48. Strmcnik, D. et al. Design principles for hydrogen evolution reaction catalyst materials. Nano Energy 29, 29-36 (2016).

49. Zheng, Y., Jiao, Y., Jaroniec, M. \& Qiao, S. Z. Advancing the electrochemistry of the hydrogen-evolution reaction through combining experiment and theory. Angew. Chem. Int. Ed. 54, 52-65 (2015).

50. Searle, P. L. The berthelot or indophenol reaction and its use in the analytical chemistry of nitrogen. Analyst 109, 549-568 (1984).

51. Watt, G. W. \& Chrisp, J. D. Spectrophotometric method for determination of hydrazine. Anal. Chem. 24, 2006-2008 (1952).

52. Li, L. et al. Two-dimensional mosaic bismuth nanosheets for highly selective ambient electrocatalytic nitrogen reduction. ACS Catal. 9, 2902-2908 (2019).

53. Bao, D. et al. Electrochemical reduction of $\mathrm{N}_{2}$ under ambient conditions for artificial $\mathrm{N}_{2}$ fixation and renewable energy storage using $\mathrm{N}_{2} / \mathrm{NH}_{3}$ cycle. $A d v$. Mater. 29, 1604799 (2017).

54. Zhao, C. et al. Ambient electrosynthesis of ammonia on a biomass-derived nitrogen-doped porous carbon electrocatalyst: contribution of pyridinic nitrogen. ACS Energy Lett. 4, 377-383 (2019).

55. Zhang, $\mathrm{S}$. et al. $\mathrm{Cu}$ doping in $\mathrm{CeO}_{2}$ to form multiple oxygen vacancies for dramatically enhanced ambient $\mathrm{N}_{2}$ reduction performance. Chem. Commun. 55, 2952-2955 (2019).

56. $\mathrm{Li}, \mathrm{W}$. et al. Nitrogen-free commercial carbon cloth with rich defects for electrocatalytic ammonia synthesis under ambient conditions. Chem. Commun. 54, 11188-11191 (2018).

57. Greenlee, L. F., Renner, J. N. \& Foster, S. L. The use of controls for consistent and accurate measurements of electrocatalytic ammonia synthesis from dinitrogen. ACS Catal. 8, 7820-7827 (2018).

58. Chen, S. et al. Room-temperature electrocatalytic synthesis of $\mathrm{NH}_{3}$ from $\mathrm{H}_{2} \mathrm{O}$ and $\mathrm{N}_{2}$ in a gas-liquid-solid three-phase reactor. ACS Sustain. Chem. Eng. 5 , 7393-7400 (2017).

59. Chen, S. et al. Electrocatalytic synthesis of ammonia at room temperature and atmospheric pressure from water and nitrogen on a carbon-nanotube-based electrocatalyst. Angew. Chem. Int. Ed. 56, 2699-2703 (2017).

60. Li, Z. et al. A silver catalyst activated by stacking faults for the hydrogen evolution reaction. Nat. Catal. 2, 1107-1114 (2019).

61. Han, Z. et al. Activated $\mathrm{TiO}_{2}$ with tuned vacancy for efficient electrochemical nitrogen reduction. Appl. Catal. B: Environ. 257, 117896 (2019).

62. Sun, Z. et al. Oxygen vacancy enables electrochemical $\mathrm{N}_{2}$ fixation over $\mathrm{WO}_{3}$ with tailored structure. Nano Energy 62, 869-875 (2019).

63. Zhang, G., Ji, Q. \& Zhang, K. Triggering surface oxygen vacancies on atomic layered molybdenum dioxide for a low energy consumption path toward nitrogen fixation. Nano Energy 59, 10-16 (2019).

64. Kresse, G. et al. Efficiency of ab-initio total energy calculations for metals and semiconductors using a plane-wave basis set. Comp. Mater. Sci. 6, 15-50 (1996).

65. Kresse, G. et al. Efficient iterative schemes for ab initio total-energy calculations using a plane-wave basis set. Phys. Rev. B 54, 11169 (1996).

66. Blöchl, P. E. Projector augmented-wave method. Phys. Rev. B 50, 17953 (1994).

67. Perdew, J. P. et al. Atoms, molecules, solids, and surfaces: applications of the generalized gradient approximation for exchange and correlation. Phys. Rev. B 46, 6671 (1992)

68. Grimme, S. et al. A consistent and accurate ab initio parametrization of density functional dispersion correction (DFT-D) for the 94 elements H-Pu. J. Chem. Phys. 132, 154104 (2010)

69. Wang, P. et al. Breaking scaling relations to achieve low-temperature ammonia synthesis through LiH-mediated nitrogen transfer and hydrogenation. Nat. Chem. 9, 64-70 (2016). 


\section{Acknowledgements}

This work was financially supported by the Natural Science Foundation of China (Grant Nos. 51872292 and 51571186), and the CAS/SAFEA International Partnership Program for Creative Research Teams of Chinese Academy of Sciences, China.

\section{Author contributions}

H.Z. and C.L. conceived the concept and experiments design. Y.Y. fabricated the catalyst. W.L. performed the material characterization and electrochemical measurements. K.L. conducted the DFT calculations. S.Z., Y.L., G.W. and H.Z. contributed to the experimental design. H.Z. supervised the research and wrote the manuscript. All authors discussed the results and commented on the manuscript.

\section{Competing interests}

The authors declare no competing interests.

\section{Additional information}

Supplementary information The online version contains supplementary material available at https://doi.org/10.1038/s42004-021-00449-7.

Correspondence and requests for materials should be addressed to C.L. or H.Z.
Reprints and permission information is available at http://www.nature.com/reprints

Publisher's note Springer Nature remains neutral with regard to jurisdictional claims in published maps and institutional affiliations.

\section{(c) (i)}

Open Access This article is licensed under a Creative Commons Attribution 4.0 International License, which permits use, sharing, adaptation, distribution and reproduction in any medium or format, as long as you give appropriate credit to the original author(s) and the source, provide a link to the Creative Commons license, and indicate if changes were made. The images or other third party material in this article are included in the article's Creative Commons license, unless indicated otherwise in a credit line to the material. If material is not included in the article's Creative Commons license and your intended use is not permitted by statutory regulation or exceeds the permitted use, you will need to obtain permission directly from the copyright holder. To view a copy of this license, visit http://creativecommons.org/ licenses/by/4.0/.

(C) The Author(s) 2021 